\title{
GRAMATICALIZACIÓN, DEBILITAMIENTO SEMÁNTICO Y REANÁLISIS. EL POSESIVO COMO ARTÍCULO EN LA EVOLUCIÓN SINTÁCTICA DEL ESPAÑOL ${ }^{1}$
}

\author{
CONCEPCIÓN COMPANY COMPANY \\ Universidad Nacional Autónoma de México
}

Es un hecho bien sabido en la teoría de cambio lingüístico que los procesos de gramaticalización operan como un canal unidireccional que en general de manera dinámica, entre otras consecuencias, desgastan significados referenciales, más concretos, y crean o recrean significados más abstractos y más gramaticales, los cuales suelen convivir durante siglos al lado de los originarios significados etimológicos referenciales. Lo que no es muy común es encontrar cambios dentro de una misma lengua que muestren de manera completa ese proceso, y donde se pueda observar y documentar, vía el análisis de contextos y de las frecuencias relativas de uso de las entidades involucradas, tanto ese simultáneo desgaste y (re)creación de las formas lingüisticas, cuanto la convivencia en un solo estado de lengua de las diferentes etapas del cambio.

La historia sintáctica del español nos proporciona un caso privilegiado de gramaticalización, privilegiado en el sentido de que es posible analizar y documentar detalladamente cómo opera un canal de gramaticalización de inicio a fin, cuáles fueron los contextos propiciadores del cambio y cuáles fueron las motivaciones, formales y semánticas, que condujeron a las etapas más innovadoras o últimas del cambio, en las cuales la forma o las formas involucradas ya se han enriquecido con nuevos significados más gramatica-

\footnotetext{
1 Una versión abreviada y preliminar de este trabajo fue leída en el $V$ Congreso Internacional de Historia de la Lengua Española celebrado en la Universidad de Valencia en febrero de 2000. Agradezco a quienes me escucharon las varias preguntas que me permitieron matizat algunos puntos. Un agradecimiento muy especial, como siempre, a mis colegas y amigas Chantal Melis y Jeanett Reynoso por la cuidadosa y crítica lectura de una versión previa. Los desaciertos, como siempre también, son responsabilidad mía.
}

$R F E$, LXXXI, 2001, 1. $.^{\circ}-2 .^{\circ}$, págs. $49-87$ 
les. El cambio específico, objetivo de este trabajo, atañe a un área básica del lenguaje humano, la deixis, en concreto aquella que involucra a dos deícticos clíticos, artículos y posesivos, focalizando de manera particular los posesivos, y muestra cómo éstos evolucionaron hasta constituirse en simples determinantes, debilitando su originario valor deíctico anafórico y también su valor posesivo. Este estudio trata de las causas, algunas de las causas al menos, que originaron la actual distribución complementaria de artículo y posesivo en la gramática del español. El cambio - un cambio único global con varios cambios específicos en su interior- fue un lento proceso de gramaticalización con un protagonista principal, el posesivo, que dura ya más de dos mil años, y que parece estar alcanzando su fin en ciertos dialectos del español. Es decir, estamos asistiendo a las últimas etapas del cambio, y tenemos además un relativo fácil acceso a sus inicios.

El estudio de las causas de la complementariedad de artículo y posesivo tiene, a mi modo de ver, un doble interés: teórico y descriptivo-diacrónico. Por una parte, los cambios quie más adelante se analizarán no sólo ejemplifican con completud un canal de gramaticalización, sino que ponen de manifiesto el distinto peso que forma y significado tienen en la generación de un cambio lingüístico; esto es, aunque las dos caras del signo lingüístico son solidarias protagonistas de los procesos de cambio, los factores formales sientan las bases, constituyen la semilla inicial, para que se produzca un cambio, pero es el significado de las formas el factor que guía la actualización del cambio y decide la nueva gramática que se generará ${ }^{2}$. El peso

\footnotetext{
${ }^{2}$ En el panorama de estudios de gramaticalización habría, al menos, cuatro posiciones teóricas, no incompatibles, sobre cómo se entabla la relación entre forma y significado en los procesos de cambio lingüístico. Una, que es la que estoy planteando aquí, que asigna distintos pesos a forma y significado, con responsabilidades distintas según la etapa del cambio, cf., por ejemplo, mis dos trabajos "The interplay between form and meaning in language change. Grammaticalization of cannibalistic datives in Spanish", Studies in Language, 1998, 22 , 3, págs. $529-565$, especialmente págs. 530-531, y "Motivaciones distintas para una gramaticalización. Español de España vs. español de México", Signo y Seña. Revista de Lingiḯstica de la Universidad de Buenos Aires, en prensa. Otra postura focaliza el significado, léxico y pragmático, como el factor que determina los cambios lingüisticos, especialmente en sus etapas iniciales, cf. entre otros, E. García y F. Van Putte, "La mejor palabra es la que no se habla", El objeto directo preposicional, C. Pensado ed., Madrid, Visor Libros, 1995 , págs. 113-131; W. Tabor y E. C. Traugott, "Structural scope expansion and grammaticalization", The limits of grammaticalization, A. G. Ramat y P. J. Hopper eds., Amsterdam, John Benjamins, 1998, págs. 229-272; E. C. Traugott, "On the rise of epistemic meanings in English. An example of subjectification in semantic change", Language, $65,1,1989$, págs. 3155. Otro acercamiento enfatiza el lado formal y sostiene que el reanálisis formal sintáctico es previo al cambio semántico; para esta tercera posición, cf. I. Roberts, "A formal account of grammaticalisation in the history of the Romance futures", Folia Linguistica Historica, 13, 1992 , págs. $219-258$, y en general los análisis en la linea de gramática generativa. Finalmente, una cuarta posición defiende que existe una coevolución, una mutua relación determinante, entre forma y significado, a mayor desgaste y cohesión formal, mayor generalización
} 
del significado no es sino consecuencia de que la sintaxis de una lengua es el nivel de simbolización o codificación de los contenidos ${ }^{3}$, y son éstos los que deciden en una gran medida el funcionamiento sintáctico. En el caso que nos ocupa, la invariabilidad formal del pronombre $s u(s)$ constituyó la motivación inicial para desencadenar una serie de cambios, pero fue la importancia semántica del poseedor y la necesidad de hacerlo explícito en la relación posesiva la causa final que terminó por incluir el posesivo en la clase de los determinantes (DET), y decidir el comportamiento del posesivo como casi un artículo en varios dialectos del español.

Los datos aportados en este trabajo tienen también interés teórico, ya que confirman la dinámica, señalada en numerosos estudios, relativa a que existe una estrecha correlación entre gramaticalización, obligatoriedad y frecuencia de empleo de una forma ${ }^{4}$ : la flexibilización de las restricciones distribucionales de un elemento conlleva un incremento en su frecuencia de aparición $\mathrm{y}$, a su vez, una mayor frecuencia es sintoma de obligatoriedad $\mathrm{y}$, por lo tanto, de un mayor grado de gramaticalización. En el cambio objeto de este trabajo, el posesivo perdió los rasgos de reflexividad y anaforicidad al sujeto que tenía en latín, flexibilizó en consecuencia sus restricciones de selección, y generalizó su empleo a un mayor número de contextos, hasta gramaticalizarse, como veremos, como un artículo peculiar en algunos dialectos del español.

Entiendo por gramaticalización un proceso dinámico constante, nunca concluido, de codificación y organización de gramática, un concepto bastante próximo al de Hopper ${ }^{5}$ de gramaticalización como creación de gramática. Gramaticalización puede cubrir, como indican los datos de este tra-

semántica, cf., entre otros, J. Bybee y W. Pagliuca, "Cross-linguistic comparison and the development of grammatical meaning", Historical semantics and historical word formation, J. Físiak ed., Berlin-New York, Mouton de Gruyter, 1985, págs. 59-83; J. Bybee, R. Perkins y W. Pagliuca, The evolution of grammar: Tense, aspect and modality in the languages of the world, Chicago, The University of Chicago Press, 1994; Ch. Lehmann, "Grammaticalization and linguistic typology", General Linguistics, 26, 1, 1986, págs. 3-22 y Thoughts on grammaticalization, Munich, Lincom Europa, 1982/1995.

${ }^{3}$ Cf. R. Langacker, Foundations of cognitive grammar, vol. 1, Theoretical prerequisites, Stanford, Stanford University Press, 1987, y Foundations of cognitive grammar, vol. 2, Descriptive application, Stanford, Stanford University Press, 1991, cap. 2.

${ }_{4}^{4}$ Para la relación entre gramaticalización y obligatoriedad del signo, cf. Bybee y Pagliu$\mathrm{ca}$, "Cross-linguistic comparison and the development of grammatical meaning", citado en la nota 2; E. Garcia, "Morphologization: A case of reversible markedness?", Probus, 3, 1, 1991, págs. 23-54; P. Hopper, "On some principles of grammaticalization", Approaches to grammaticalization, E. C. Traugott y B. Heine eds., Amsterdam, John Benjamins, vol. 1, 1991, págs. 17-35, y Ch. Lehmann, "Grammaticalization and linguistic typology", y Thoughts on grammaticalization, citados en la nota 2 .

${ }^{5}$ En su artículo de 1987, "Emergent grammar", Berkeley Linguistics Society, 13, págs. 139-157. 
bajo, varios procesos de cambio que se involucran en un mismo canal diacrónico unidireccional, en el cual el nuevo valor avanza lenta y progresivamente a contextos cada vez más favorables a ese nuevo valor; los cambios no implican necesariamente un cambio externo, formal, de las entidades involucradas ${ }^{6}$. La consecuencia de una gramaticalización es variación sincrónica y análisis conflictivos, en cuanto que una misma forma o construcción acepta dos o más interpretaciones simultáneas, de manera que el valor conservador etimológico y el innovador pueden convivir por siglos bajo un mismo exponente formal, tal como sucede con la sintaxis del pronombre posesivo en el español. A su vez, la variación sincrónica es síntoma y requisito para que se prođuzca una gramaticalización; esto es, gramaticalización y variación sincrónica se determinan mutuamente, borrándose los límites entre diacronía y sincronía. En el cambio específico que nos ocupa, la variación sincrónica reflejada en el español americano no sólo permite un mejor entendimiento de los procesos diacrónicos involucrados, sino que aporta una evidencia preciosá para asomarnos a los estados de lengua más innovadores de la gramaticalización del posesivo como DET. Sin esos datos dialectales nuestra comprensión de esta área de la sintaxis histórica del español sería mucho más limitada.

Por otra parte, más allá de la teoría, el análisis de las causas que motivaron la actual distribución complementaria de artículo y posesivo tiene interés en sí mismo, ya que puede arrojar luz sobre las conexiones que la construcción $\mathrm{ART}+\mathrm{POS}+\mathrm{N}$ tenía con otras zonas de la posesión nominal, $\mathrm{y}$ puede permitir, por tanto, un mejor conocimiento de esta construcción tan característica del español medieval.

El trabajo, además de la presente introducción, está estructurado en cinco apartados. En el primero se plantean el objetivo, la hipótesis y los cambios lingüísticos base del análisis, así como una brevísima revisión de la bibliografia existente sobre esos cambios, ya que ella nos permite ubicar nuestro trabajo con respecto al estado de la cuestión. En el apartado 2 realizo una caracterización sintáctico-semántica de las diferencias y afinidades entre artículo y posesivo, las cuales son el punto de partida para comprender las transformaciones que experimentó el pronombre posesivo en la evolución sintáctica del español. En el apartado 3 aparece el análisis de las causas de los cambios que llevaron al cambio central objeto de este trabajo, y se muestra, con base en la frecuencia relativa de uso de las diversas construcciones posesivas involucradas, un correlato interesante entre la pérdida de una de las construcciones y la extensión de otras estructuras pose-

${ }^{6}$ Cf. J. Kurylowicz, "The evolution of grammatical categories", Esquisses linguistiques, Munich, Fink, vol. 2, 1965/1976, págs. 38-45. 
sivas de débil valor anafórico posesivo. En 4 se exponen y ejemplifican las diversas etapas del cambio que constituyen el canal de gramaticalización aquí planteado, en el cual es posible observar cómo la forma $s u(s)$ amplió su semántica, añadiendo a su originario valor anafórico posesivo un significado más abstracto de presentador de entidades nominales. En el apartado 5 se analizan otras construcciones posesivas medievales que parecen constituir, al menos a primera vista, un residuo para la hipótesis que sustenta este trabajo, y se muestra que no constituyen un verdadero contraejemplo. Finalmente, apartado 6, se plantean unas conclusiones, que son tanto un resumen de lo visto, como algunas reflexiones de carácter teórico sobre la relación entre gramaticalización y los aspectos concretos de la sintaxis histórica del español concernientes a este cambio.

El corpus en que se basa la investigación abarca tres momentos: ocho textos medievales, comprendidos entre los siglos XIII-Xv ${ }^{7}$, lapso en que se puede documentar la paulatina pérdida de la construcción $A R T+P O S+N$, seis textos del siglo XVI, peninsulares y americanos novohispanos, período que se muestra como particularmente interesante para nuestro objetivo, ya que constituye el último momento de documentación de las FNs encabezadas por los dos clíticos ${ }^{8}$ y empiezan a extenderse FNs encabezadas por posesivo, pero de muy débil valor anafórico posesivo, y, finalmente, diversos textos orales y escritos de fines del siglo $\mathrm{xx}$, mayoritariamente mexicanos, en los cuales se puede documentar con facilidad la etapa más innovadora o última del canal de gramaticalización que analizaremos, ya que el posesivo empieza a mostrarse en este dialecto como un simple presentador de la $\mathrm{FN}$, muy próximo a un artículo ${ }^{9}$.

\footnotetext{
${ }^{7}$ No obstante la polémica asignación cronológica del Cantar de mio Cid, para los fines de este trabajo, y con el fin de no atomizar excesivamente los datos, consideraré este texto como perteneciente al siglo Xill.

${ }^{8}$ Cf. $\mathrm{H}$. Keniston, The syntax of Castilian prose. The sixieenth century, Chicago, Chicago University Press, 1937, en especial las págs. 245-247, y X. Jiménez, Las FNs con articulo + posesivo en el español medieval. Estructura y diacronia, tesis de Jicenciatura inédita, México, UNAM, 2000.

${ }^{9}$ El corpus base del anátisis para los diferentes siglos es: siglo $\mathrm{xIII}:$ Cid $=$ Cantar de mio Cid, edición paleográfica de R. Menéndez Pidal, vol. 3 de Cantar de mio Cid. Texto, gramática y vocabulario, Madrid, Espasa Calpe, 1944; Calila = Calila e Dimna, edición de J. M. Cacho Blecua y M. J. Lacarra, Madtid, Castalia, 1987; GEII = Alfonso x El Sabio, General estoria. Segunda Parte, edición de A. G. Solalinde, Ll. A. Kasten y V. R. B. Oelschläger, Madid, cSIC, 1957. Siglo xIV; Lucanor = Don Juan Manuel, El conde Lucanor o Libro de los enxiemplos del conde Lucanor et de Patronio, edición de J. M. Blecua, Madrid, Castalia, 1969; Pedro I = Crónica del rey don Pedro I, edición de C. L. Wilkins y H. M. Wilkins, Madison, The Hispanic Seminary of Medieval Studies, 1985. Siglo xv: Enrique Iv = Crónica anónima de Enrique $\mathrm{V}$ de Castilla, 1454-1474 (crónica castellana), edición de M. P. Sánchez-Parta, Madrid, Ediciones de la Torre, 1991; RRCC = Hernando del Pulgar, Crónica de los Reyes Católicos, vol. 2. Guerra de Granada, edición de J. de Mata Carriazo, Madrid, Espasa
} 


\section{OBJETIVO E HIPÓTESIS}

El objetivo de este trabajo es intentar formular una explicación de por qué el posesivo y el artículo llegaron a estar en la gramática del español en distribución complementaria. Esto es, en la mayoria de dialectos del español, artículo y posesivo terminaron excluyéndose e imposibilitados de construirse juntos en una misma frase nominal $(\mathrm{FN})^{10}$, tal como to hacian en el español antiguo.

La consecuencia, como se sabe, fue que la clase gramatical DET se amplió en la historia del español vía la inclusión del posesivo en esta categoría. En efecto, de tener el español medieval sólo dos formas para la expresión de la determinación: artículo y demostrativo ", pasó a tener tres formas: artículo, posesivo y demostrativo. El proceso, como ya comenté, fue un paulatino desgaste de la deixis anafórica originaria del pronombre posesivo, que le permitió gramaticalizarse como DET y ampliar por tanto su espectro funcional. Ambas formas, artículo y posesivo, fueron, sin duda, protagonistas de este cambio, pero el gran "responsable", como intentaré mostrar, fue el posesivo, ya que fue este pronombre el que en la historia del

Calpe, 1943; Celestina = Fersando de Rojas, La Celestina. Tragicomedia de Calisto y Melibea, edición de M. Marciales, concluida por B. Dutton y J. Snow, Urbana y Chicago, University of Illinois Press, 1985. Siglo xvI: Cortés (cartas 1, 2 y 3) $=$ Hernán Cortés, Cartas y documentos, edición de $\mathrm{M}$. Hernánđez Sánchez Barba, México, Porrúa, Biblioteca Porrúa, 1963, págs. 3-202; DLNE = Concepción Company Company, Documentos lingüisticos de la Nueva España (1525-1818) (Altiplano Central), México, UNAM, 1994, siglo xvI: págs. 23-239; Lozana = Francisco Delicado, Retrato de la Lozana Andaluza, edición de Claude Allaigre, Madrid, Cátedra, Col. Letras Hispánicas, 1985; Lazarillo = Anónimo, Tri-linear edition of Lazarillo de Tormes of 1554 (Burgos, Alcalá de Henares, Amberes), edición de J. V. Recapito, Madison, The Hispanic Seminary of Medieval Studies, 1987; Emigrantes = Enrique Otte, Cartas privadas de emigrantes a Indias (1540-16I6), con la colaboración de Guadalupe Albi, Sevilla, v Centenario, Junta de Andalucía, Escuela de Estudios Hispanoamericanos, 1988, cartas de México, págs. 39-173 (1556-1590); Bernal = Bernal Díaz del Castillo, Historia verdadera de la conquista de la Nueva España, edición de C. Sáenz de Santamaría, México, Alianza Universidad, 1991. Siglo Xx: El habla de la ciudad de Madrid (habla culta). Materiales para su estudio, coordinación y edición de M. Esgueva y J. Cantarero, Madrid, CsIC, 1981; El habla de la ciudad de México (habla culta). Materiales para su estudio, coordinación y edjción de Juan M. Lope Blanch, México, Universidad Nacional Autónoma de México, 1971; El habla popular de la ciudad de México. Materiales para su estudio, coordinación y edición de Juan M. Lope Blanch, México, Universidad Nacional Autónoma de México, 1976; diversos números de los periódicos El Financiero, La Jornada, El Pais (enero-febrero 1999).

${ }^{10} \mathrm{Se}$ mantiene en varias modalidades regionales rurales del norte y occidente de España, Asturias, Santander, Extremadura, León, Burgos, Salamanca, cf. E. Pato, "Sobre el artículo con posesivo en español medieval", manuscrito inédito, 1999, en especial la nota 12, que ofrece una amplia revisión dialectal, y A. Zamora Vicente, Estudios de dialectología hispáni$c a$, Santiago de Compostela, Publicaciones de la Universidad de Santiago, 1986 (Verba, anexo 25), especialmente las págs. 50-55.

"Cf. C. Company, La frase sustantiva en el español medieval, Cuatro cambios sintácticos, México, UNAM, 1992, capítulo 2. 
español se aproximó semánticamente, y por lo tanto, también sintácticamente, al artículo, y no éste al posesivo. Con respecto a sus étimos latinos, ille y suus, tanto el artículo como el posesivo extendieron enormemente su empleo en el español ${ }^{12}$, sin embargo sólo una de las extensiones, la del posesivo, fue, según creo, la causante principal de la actual distribución complementaria de los dos clíticos nominales, ya que conllevó, entre otras consecuencias, un debilitamiento y pérdida del valor anafórico reflexivo originario, debilitamiento que se incrementó y terminó por desgastar enormemente el valor anafórico posesivo del pronombre $s u(s)$. Tal debilitamiento fue, en mi opinión, el gran motivador, y responsable inicial, de una serie de cambios que culminan con la exclusión sintagmática de artículo y posesivo. También, importantes afinidades semánticas y funcionales entre las dos formas reforzaron el conocido resultado de distribución complementaria de artículo y posesivo; esto es, era un tanto antieconómico, en el sentido de Haiman ${ }^{13}$, encabezar una $\mathrm{FN}$ con dos clíticos de valor muy similar. Es decir, la pérdida de las construcciones del tipo lá su casa fue ocasionada por un cambio multicausal en el que interactúan dos motivaciones generales, tal como aparece formulado en la siguiente hipótesis.

HIPÓTESIS: En la desaparición de construcciones nominales del tipo $A R T+P O S+N$ estuvieron en juego y actuaron de manera conjunta, al menos, dos causas generales: a) una, con ángulos múltiples y varios cambios en juego, que se puede caracterizar como debilitamiento del valor anafórico y posesivo del pronombre posesivo, causa fundamental a mi modo de ver, y b) otra que se puede caracterizar como una motivación económica, dada la afinidad semántica de las frases introducidas por artículo y posesivo.

Bajo (1) aparecen ejemplificadas las diferentes posibilidades sintagmáticas, bien conocidas, de artículo y posesivo en el español, que constituyen el sustento para la hipótesis y el punto de partida para el análisis, en cuanto que son ejemplos tipo que muestran las semejanzas y diferencias estructurales entre artículo y posesivo. Los dos primeros ejemplos presentan dos empleos típicos del artículo: referencial definido (la) y genérico (1b). En (1c) se ejemplifica el uso general más extendido del posesivo: anafórico al sujeto, de puso y fuesse, respectivamente. El ejemplo (1d) muestra un em-

12 Cf. M. Bassols de Climent, Sintaxis latina, Madrid, CSIC, 1956, 2 vols, esp. vol. I, págs. 178 y 191.

${ }^{13}$ Cf. J. Haiman, Natural syntax. Iconicity and erosion, Cambridge, Cambridge University Press, 1985, especialmente págs. 157, 160, y también M. Haspelmath, "Explaining article-possessor complementarity: Economic motivation in noun phrase syntax", Language, 75, 2, 1999 , págs. 227-243, esp. pág. 231 . 
pleo no anafórico, sino catafórico a un poseedor nombrado tras la FN poseida. En (le) se ejemplifica la concurrencia de artículo y posesivo en una misma FN. Finalmente (1f) y (1g) muestran dos construcciones posesivas que hacen explícita la referencia al poseedor dentro de su propia FN, bien con una frase prepositiva (FP) adnominal (1f), bien con una oración relativa especificativa (le), que vincula la referencia al poseedor mediante información morfológica, la desinencia verbal de persona.

(1) (a) Que el triste de nuestro amo es caydo del escala y no habla ni se bulle (Celestina, XIX.32.250).

(b) Pues dame agora enxemplo del omne que faze las cosas sin alvedrío (Calila, 263).

(c) Puso en su coraçon de se guardar et de lo provar, et fuesse para su casa (Lucanor, XLII.210).

(d) ¿No oiste dezir: dormieron su sueño los varones de las riquezas? (Celestina, IV.38.81).

(e) El buen Campeador la su cara tornava (Cid, 594).

(f) E vino a su tierra de las amazonas sin sospecha, e fallolas aseguradas e desarmadas (GEII, 21.9a).

(g) Mas non fue asi, ca metio Philomena mano a su cuchiello que traye e degoll de oreia a oreia (GEIl, 257.16b).

Para sustentar la hipótesis, en especial el peso de la causa primera, analizaré diversos cambios sintácticos del español que involucran al posesivo, bien de manera aislada, bien en concurrencia con el articulo, aparentemente inconexos, pero que, bajo una mirada atenta, todos ellos muestran un mismo y único proceso diacrónico subyacente, a saber, un canal de gramaticalización de desgaste del significado referencial deíctico anafórico del posesivo y ganancia del significado gramatical de DET. Bajo (2) aparecen listados los cambios base del análisis, los cuales se corresponden en esencia con los ejemplos de (1). Por el momento, sólo atenderé a los cambios de manera global, focalizando aquellos aspectos que muestran el camino diacrónico a través del cual el artículo y el posesivo terminaron por entrar en distribución complementaria, y pasaré por alto los detalles y las motivaciones específicas de cada uno de esos cambios.

(2) (a) Pérdida de FNs introducidas por ART+Pos: la su cara (le).

(b) Incremento de FNS del tipo $\mathrm{SU}+\mathrm{N}+\mathrm{DE}+\mathrm{N}-\mathrm{POSEEDOR}$ : su tierra de las amazonas (1f).

(c) Incremento de FNs del tipo SU+N+OR RELATIVA ESPECIF: $s u$ cuchiello que traye $(\mathrm{lg})$. 
(d) Incremento de usos catafóricos del posesivo: dormieron su sueño los varones (1d).

La atención prestada a las construcciones involucradas en estos cambios ha sido en general escasa, y la mayoría de las veces el énfasis ha recaído en su comportamiento sincrónico en algún estado de lengua en el español medieval, más que en las causas de su evolución diacrónica. En cuanto al primer cambio (2a), las construcciones del tipo la su cara han merecido tres tratamientos en la bibliografia especializada: uno que podría llamarse tradicional, uno funcionalista y uno en el ámbito de la gramática generativa. El enfoque tradicional las define como una estructura reacia a generalizaciones, cuya caracterización se sitúa más en un nivel estilístico que propiamente gramatical, debido a las "grandes diferencias que se presentan no sólo entre autores de un mismo período, sino dentro de un mismo autor, o incluso entre pasajes de una misma obra", como señala Lapesa ${ }^{14}$, o como afirma Meier "ha grandes divergencias de gosto pessoal dos autores" ${ }^{15}$. Todos los trabajos en este enfoque las caracterizan como formas para énfasis y realce expresivo, y constatan el paulatino decremento de estas construcciones hasta su desaparición a fines del siglo xvi. Por su parte, los estudios de corte funcionalista estructural se proponen explicar las causas de la distribución complementaria de artículo y posesivo, y focalizan para ello los rasgos léxicos inherentes de las FNS introducidas por estos clíticos, fundamentalmente proponen dos causas: las afinidades semánticas en términos de definitud y las diferencias en capacidad anafórica de articulo y posesivo. Según los estudiosos adscritos a este enfoque, esas dos causas permitirian explicar tanto la posibilidad que tienen artículo y posesivo de construirse juntos en el español medieval y en un cierto número de lenguas, cuanto su incompatibilidad en el español actual y en la mayoría de lenguas del mundo ${ }^{16}$. Recientemente, trabajos en la línea de la

\footnotetext{
${ }^{14}$ Cf. su artículo de 1971, "Sobre el artículo con posesivo en castellano antiguo", recogido en R. Lapesa, Estudios de morfosintaxis histónica del español, Madrid, Gredos, 2000, vol. 1, págs. 413-435, especialmente la pág. 413.

is $\mathrm{Cf}$. H. Mejer, "Meu pai-o men pai. $\mathrm{O}$ artigo antes de adjetivo possessivo + nome de parentesco na linguagen falada", Boletim de Filologia, IX, fascículo 2, 1948, págs. 175-190, esp. pág. 179. En la misma linea de caracterización estilistica, cf. R. Cano Aguilar, El español a través de los tiempos, Madrid, Arco Libros, 1988, pág. 42; G. Clavería, "La construcción artículo+posesivo en los siglos XIV y XV", Actas del h Congreso Internacional de Historia de la Lengua Española, Madrid, Arco Libros, vol, 1, 1992, págs. 347-357; L. Terracíni, "L'uso dell'articolo davanti al possessivo nel Libro de buen amor", Publicazioni della Facol tá di Letre e Filosofia, Universitá de Torino, II, 5, 1951.

${ }^{16} \mathrm{Cf}$. para este segundo enfoque en una perspectiva tipológica, T. Givón, Functionalism and grammar, Amsterdam, John Benjamins, 1995, pág. 179; y el articulo de Haspelmath, "Explaining article-possessor complementarity", citado en la nota 12. Para el español, cf. Company, La frase sustantiva en el español medieval, cap. 2, citado en la nota 10.
} 
gramática generativa han puesto la atención en cuáles fueron los procesos que llevaron al llenado léxico de la categoría gramatical DET, nodo $\mathrm{D}$ en su terminología, en el español. El artículo primero y el posesivo después habrían experimentado un movimiento ascendente hacia el nodo superior $\mathrm{D}$, abandonando su estatus argumental originario, próximo a deícticos demostrativos ya que se generaban en un nodo inferior DEM ${ }^{17}$. Este movimiento sintáctico ascendente, similar en los dos clíticos, habría provocado la actual distribución complementaria de artículo y posesivo en el español.

Los cambios consignados en (2b-d) han sido objeto de mucha menor atención. Las FNs que duplican la referencia al poseedor en su misma FN, vía una $\mathrm{FP}$ adnominal ( $2 \mathrm{~b}$ ), vía una oración relativa especificativa $(2 \mathrm{c})$, suelen merecer si acaso un brevísimo comentario cuando se aborda la posesión simple, su casa, y suelen ser calificadas de construcciones pleonásticas o redundantes ${ }^{18}$, o agramaticales ${ }^{19}$, que sólo contribuyen a paliar la ambigüedad provocada por la polisemia referencial del pronombre $s u(s)$. En los últimos años se ha abordado el análisis diacrónico de estas construcciones por sí mismas, mostrando que tienen un valor semántico posesivo propio, frente a las FNS equivalentes encabezadas por articulo, y que existen razones estructurales específicas para su peculiar desarrollo en el español americano ${ }^{20}$. Los empleos catafóricos del posesivo y su incremento en la his-

${ }^{17}$ Cf. M. Batllori y F. Roca, "The value of Ds from Old Spanish to Modern Spanish", Diachronic syntax: Models and mechanisms, S. Pintzuk, G. Tsoulas y A. Warner eds., Oxford, Oxford University Press, en prensa.

${ }^{18} \mathrm{Cf}$., por ejemplo, Cano Aguilar, El español a través de los tiempos, citado en la nota 14 , pág. $142 ; \mathrm{R}$. J. Cuervo, Diccionario de construcción y régimen de la lengua castella$n a, 2$ vols., Paris, A. Roger y F. Chernoviz, 1886-1893; S. Fernández Ramírez, Gramática española, vol. 3, 2, El pronombre, Madrid, Arco Libros, 1951/1987, pág. 86; Keniston, The syntax of Castilian prose. The sixteenth century, citado en la nota 8, pág. 244; M. J. Martínez Alcalde, Morfologia histórica de los posesivos españoles, Valencia, Universitat de Valencia, 1996 (Cuadernos de Filología, 19), págs. 78-79; W. Meyer-Lübke, Grammaire des langues romanes, Genève-Marseille, Slatkine-Laffitte Reprints, 1890-1906, 3 vols., especialmente, vol. III, págs. 92-93.

19 "Incompatibilidad" es la caracterización más común para las FNS encabezadas por posesivo que contienen una oración relativa especificativa, cf. J. M. Brucart, "Sobre una incompatibilidad entre posesivos y relativas especificativas", Gramática del español, V. Demonte ed., México, El Colegio de México, págs. S1-86; C. Picallo y G. Rigau, "El posesivo y las relaciones posesivas", Gramática descriptiva de la lengua española, I. Bosque y V. Demonte, dirs., Madrid, Espasa Calpe, vol. 1, 1999, págs. 973-1023, especialmente la pág. 978. Las gramáticas de referencia no suelen mencionarlas, cf. E. Alarcos Lloracb, Gramática de la lengua española, Madrid, Espasa Calpe-Real Academia Española, 1994, esp. las págs. 331-339; Real Academia Española (RAE), Esbozo de una nueva gramática de la lengua española, Madrid, Espasa Calpe, 1973, especialmente págs. 524-535.

${ }^{20}$ Cf. los artículos de C. Company, "Semántica y sintaxis de los posesivos duplicados en el español de los siglos xv y xv", Romance Philology, 48, 2, 1994, págs. 111-136; "Cantidad vs. cualidad en el contacto de lenguas. Una incursión metodológica en los posesivos "redundantes» del español americano", Nueva Revista de Filología Hispánica, 43, 2, 1995, 
toria del español (2d) son aspectos que pasan en general inadvertidos en los estudios sobre posesión en español ${ }^{21}$.

Los diversos análisis hasta aquí reseñados de las construcciones que sustentan los cambios consignados en (2) creo describen acertadamente los hechos diacrónicos y son esencialmente correctos: los sintagmas del tipo la su cara se perdieron ya que artículo y posesivo portan valores semánticos afines; la ambigüedad de $s u(s)$ generó sintagmas peculiares, muy sobreespecificados, de apariencia redundante. Sin embargo, esos análisis son también, a mi modo de ver, esencialmente insuficientes en cuanto que las diversas construcciones se han considerado de manera aislada, pasando por alto sus interrelaciones y el encadenamiento dinámico de esos cuatro cambios, y pasando por alto sobre todo la responsabilidad que tuvo el posesivo en la pérdida de las construcciones nominales encabezadas por ART+POS. Mostrar esas interrelaciones y el papel protagónico del posesivo es justamente el objetivo de este trabajo.

\section{CARACTERIZACIÓN SINTÁCTICO-SEMÁNTICA DE ARTÍCULO Y POSESIVO}

Artículo y posesivo muestran en la historia del español diferencias importantes, que les permitieron construirse juntos en una misma FN durante un largo periodo de la historia del español, pues la presencia de una forma no inhibia la presencia de la otra, diferencias que fueron al mismo tiempo un factor para el cambio, y muestran también estrechas afinidades semánticas, que constituían, sin duda, un factor de debilidad estructural para la convivencia sintagmática de los dos clíticos.

Veamos:

A) Diferencias. Aunque ambos, artículo y posesivo, son deícticos, el primero sólo tiene una tarea que realizar, mientras que el segundo tiene dos

págs. 305-339; "Old forms for new concepts. The recategorization of possessive duplication in Mexican Spanish", Historical linguistics 1993, H. Andersen ed., Amsterdam, John Benjamins, 1995, págs. 77-93. Cf. también, Picallo y Rigau, "El posesivo y las relaciones posesivas", citado en la nota 18, y D. Reyes, Posesivos y relativas especificativas en el español, tesis de licenciatura inédita, México, UNAM, 2000.

${ }_{21}$ No lo comentan Picalio y Rigau "El posesivo y las relaciones posesivas", citado en la nota 18; tampoco J. A. Porto Dapena, "Los posesivos personales del español: intento de descripción funcional", Dicenda, 1, 1982, págs. 55-108; F. Satorre Grau, Los posesivos en espanol, Valencia, Universitat de Valencia, 1999 (Cuadernos de Filología, 35); B. Radelli, "Los posesivos en español", Nueva Revista de Filologia Hispánica, 27, 2, 1978, págs. 235-257. Ha merecido un breve comentario en Company, "Su casa de Juan. Estructura y evolución de la duplicación posesiva en español", Actas del I Congreso Anglo Hispano, R. Penny ed., Madrid, Castalia, 1993, págs. 73-88, y una mención en Batllori y Roca, "The value of Ds from Old Spanish to Modern Spanish", citado en la nota 16 . 
tareas. La función esencial y única del artículo es presentar la entidad nominal que sigue como determinada, conocida, accesible al oyente y próxima a la experiencia ${ }^{22}$; es un deíctico que busca su relación hacia adelante en el sintagma, lo podríamos denominar deixis prospectiva, y una vez que presenta a su nominal no queda ningún residuo informativo pendiente, por lo cual esas FNS son autónomas referencialmente y no relacionales.

Por el contratio, el posesivo, como cualquier anáfora, tiene dos funciones que realizar: presentar a la entidad poseída, tarea similar a la del artículo, pero también simultáneamente debe buscar y anclar la referencia del poseedor de esa entidad poseída fuera de su propia $\mathrm{FN}$, por lo regular en la información previamente dada; se podria denominar deixis retrospectiva. Por ello, cuando se emite una $\mathrm{FN}$ encabezada por posesivo queda una información pendiente: cuál es el poseedor, información que debe ser completada en el contexto, y por tanto esas FNs son relacionales y no autónomas referencialmente.

En (3) aparecen algunos ejemplos que muestran este contraste funcional, y ejemplifican el uso típico de artículo y posesivo. El primero (3a) no requiere información fuera de su FN, pues una vez presentado el nominal, el oyente posee toda la información necesaria para la adecuada comprensión de esa FN; es decir, el empleo del artículo garantiza que el nominal es totalmente accesible al oyente. El posesivo, en cambio, (3b), introduce una información adicional, 'poseído de', que obliga al oyente a recuperar en el contexto ese contenido adicional que es el vínculo con el poseedor. En (4) aparece un par mínimo que muestra un cambio de significado del sustantivo provocado por la alternancia del clítico: la FN con artículo (4a) es informativamente completa, la encabezada por posesivo (4b) no lo es, ya que requiere de un anclaje referencial con un poseedor, y por ello automáticamente se le asigna una lectura relacional de «poseido de» al sustantivo, con un consecuente cambio de significado como primera lectura espontánea de la FN. Participa el pronombre posesivo español de una característica de la posesión nominal muy extendida tipológicamente, y es que por lo regular los posesivos aportan una información bastante vaga que requiere, para completarse, de contexto, lingüístico y extralingüístico, y muchas veces es

\footnotetext{
22 Para la semántica del artículo, remito a A. Alonso, "Estilistica y gramática del artículo en español", Estudios lingüisticos, vol. 1, Temas españoles, Madrid, Gredos, 1933/1974, págs. 125-160, especialmente pág. 134; C. Company, "La extensión del artículo en el español medieval", Romance Philology, 44, 4, 1991, págs. 402-424; R. Epstein, "The development of the definite article in French", Perspectives on grammaticalization, W. Pagliuca ed., Amsterdam, John Benjarnins, 1994, págs. 63-81, en particular pág. 75; M. Leonetti Jungl, El articulo y la referencia, Madrid, Taurus, 1990, en especial el cap. 3; G. L. Trager, The use of the Latin demonstratives (especially "ille" and "ipsen) up to 600 A.D., as the source of the Romance article, New York, Publications of the Institute of French Studies Inc., 1932, especialmente las págs. 37 y ss. y 105.
} 
una información inferida o presupuesta, más que realmente explicitada ${ }^{23}$. E1 ejemplo de (4b) confirma esa caracterísica de vaguedad del posesivo y de necesidad de información extratextual. Como veremos, esa vaguedad puede entorpecer el éxito comunicativo ${ }^{24}$, y se convierte en un disparador potencial de cambios diacrónicos.

(3) (a) Tengo por bien que nos ayuntemos, nos et el camello (Calila, 160).

E a muchos annos que non llueve otrossi en las tierras de Egipto (GEII, 23.6a).

(b) Coiamos $l o s_{\mathrm{i}}$ de dentro, ca el sennorio tenemos, posaremos en $s u s_{\mathrm{i}}$ casas et dellas nos serviremos (Cid, 622).

De lo que contesçio a un mercadero ${ }_{\mathrm{i}}$ quando fallo $a s u_{\mathrm{i}} m u$ ger et $s u_{i}$ fijo durmiendo en uno (Lucanor, XXXVI, 193).

(4) (a) Se desmayó estando en el juicio.

(b) Se desmayo estando en su juicio.

La autonomía referencial y accesibilidad total de las entidades encabezadas por artículo y la falta de autonomía y accesibilidad por parte del posesivo provoca que el primer clítico, pero no el segundo, pueda presentar FNS genéricas, dependientes muchas veces de conocimiento de mundo no explicito lingüísticamente: en (5a) existe la información implícita "la población mundial se compone de mujeres y hombres", "la población mundial no sólo se compone de mujeres", y FNs no anafónicas basadas en la situación $(5 b)^{25}$. El posesivo, en cambio, no admite usos genéricos y ancla siempre a su nominal en el contexto lingüistico específico.

(5) (a) Las mujeres constituyen el sesenta por ciento de la población mundial.

(b) Espere la señal antes de marcar (apud Leonetti) ${ }^{26}$.

\footnotetext{
${ }^{23}$ Cf. B. Heine, Possession. Cognitive sources, forces and grammaticalization, Cambridge, Cambridge University Press, 1997, especialtnente págs. 26-27 y 143.

${ }^{24}$ Para el concepto de éxito comunicativo y su relación con los procesos de cambio, cf. R. Keller, "Towards a theory of linguistic change", Linguistics dynamics. Discourses, procedures and evolution, Th. T. Ballmer ed., Berlin-New York, Walter de Gruyter, 1985, en particular las págs. 211 y 238, y del mismo autor On language change. The invisible hand in language, London-New York, Routledge, 1995, especialmente las págs. 106-110.

${ }^{25}$ Cf. M. Leonetti Jungl, "El articulo", Gramática descriptiva de la lengua española, I. Bosque y V. Demonte, dirs., Madrid, Espasa Calpe, vol. 1, 1999, págs. 787-890; en particular las págs. 797-799 y 801.

${ }^{26}$ El artículo de este autor citado en la nota anterior, pág. 798.
} 
El contraste entre ambos clíticos aparece resumido en (6).

(6) DIFERENCIAS ENTRE ARTICULO Y POSESIVO
ARTÍCULO
POSESIVO
Deictico prospectivo
Deíctico retrospectivo.
No relacional
Relacional
FN informativamente autónoma
Accesibilidad total
FN informativamente no autónoma
Sin anclaje referencial externo
Lecturas genéricas
No accesibilidad total
Empleos situacionales
Con anclaje referencial externo
No lecturas genéricas
No empleos situacionales

Los datos del corpus sugieren que diacrónicamente el pronombre posesivo alteró en su evolución sintáctica el equilibrio entre sus dos funciones esenciales: debilitó su función relacional anafórica y fortaleció su función presentativa, con lo cual se aproximó al artículo, entró en distribución complementaria con él y terminó por incluirse en la clase de los determinantes.

B) Afinidades. Muestran artículo y posesivo similitudes formales y semánticas. En el nivel formal, ellos son los dos únicos integrantes de la estructura de la FN que no son palabras, sino clíticos, y ambas formas comparten en lo esencial una distribución semejante en cuanto a la concurrencia con otros modificadores del núcleo de una $\mathrm{FN}^{27}$. En el nivel semántico, más importante para nuestro análisis, ambos clíticos introducen por lo regular FNS definidas, especificadas, cuyos referentes son perfectamente identificables por hablante y oyente dentro de una determinada situación comunicativa (7a), y conllevan una información compartida y conocida por ambos, esto es tienen anclaje pragmático ${ }^{28}$. En el cuadro 1 de abajo se muestra la frecuencia de uso de FNS definidas vs. no definidas documentadas en el periodo inicial del corpus, y se confirma la alta preferencia de las FNs poseídas por ser definidas. Este comportamiento semántico afín se manifiesta también en frecuentes alternancias de artículo y posesivo en contextos casi idénticos, introduciendo el mismo tipo de entidades nominales (7b), y se manifiesta también en el intercambio, sustitución u omisión de alguno de los clíticos que con bastante frecuencia realizan los distintos manuscritos o ediciones de un mismo texto, cuando es posible, claro está, tener acceso

\footnotetext{
${ }^{27}$ Cf. Company, el libro citado en la nota 10 , págs. 69-70.

${ }^{28}$ Cf. J. A. Hawkins, Definiteness and indefiniteness: A study in reference and grammaticality prediction, London, Croom Helm, 1978.
} 
a este tipo de ediciones críticas (7c). Es importante en este punto señalar que en las construcciones del tipo la su cara, en el corpus del siglo XIII, las ediciones críticas consultadas, omiten con más frecuencia el artículo (12\%, 58 omisiones sobre un conteo de 495 FNs con art+pos) que el posesivo $(6 \%, 31$ omisiones). Ello quiere decir que o bien son FNS de significado relacional posesivo, y el artículo es un tanto innecesario, o bien que informativamente es más importante mantener el anclaje con el poseedor que presentar el nominal.

(7) (a) Martin Antolinez un colpe dio a Galve, ..., cortol el yelmo, que llego a la carne (Cid, 1055).

Escrivien cartas, bien las sello... Al rey ondrado le echaron las cartas (Cid, 1956-1958).

Quando el Mal entendio que el Bien dizía verdat et que $s u$ fijo sería muerto (Lucanor, XLIII, 215).

La una es que algunos ponen todo su talante et su entendimiento en las cosas del mundo... et en complir sus voluntades en qualquier manera que pueden (Lucanor, Quinta parte, 301-302).

(b) Et puso sus pies en dos cosas a que se afirmó, et eran quatro culebras que sacaban sus cabeças de sus cuevas... et olvidó de commo tenía los pies sobre las culebras (Calila, 120).

Aqui reçiben las fijas del Campeador (Cid, 2584).

Por que escurren sus fijas del Campeador a tierras de Carrión (Cid, 2590).

(c) Fasta que toda la huest, con todas las sus cosas, fueron passados al otra parte (GEII, 16.30a).

Ms. t: las omitido.

E pensando en el dicho daquella voz que podrie seer, vinol por ell aer Pallas, a quien los gentiles llamavan la su deessa de las batallas (GEII, 64.1b).

Mss. I, $\Omega$ : la omitido.

Que assi non nos parte de seer todos de un Dios e seguir los sus mandamientos (GEII, 108.8a).

Ms. J: sus omitido.

Conjurote, triste Plutón... administrador de todas las cosas negras del reino de Estigie y Dite, con todas sus lagunas y sombras infernales (Celestina, III.41.71).

Ed. L: con todas las lagunas. 
CUADro 1

FNS DEFINIDAS CON ARTíCULO Y POSESIVO: SIGLO XIII (conteos realizados sobre 500 FNs para cada clítico)

\begin{tabular}{lll}
\hline & ARTICULO & POSESIVO \\
\hline DEFINIDAS & $81 \%(406 / 500)$ & $98 \%(492 / 500)$ \\
No DEFINIDAS & $19 \%(94 / 500)$ & $2 \%(8 / 500)$ \\
\hline
\end{tabular}

Participa el español, como indica el cuadro anterior, de una característica tipológica común para artículos y posesivos en las lenguas del mundo ${ }^{29}$, a saber, que sus FNs suelen ser mayoritariamente definidas. Dadas estas semejanzas funcionales semánticas, parece innecesario cubrir dos veces la posición estructural DET con dos formas que conllevan el mismo tipo de información. Esto es, si las FNS poseídas tienen una elevada preferencia por ser determinadas, la presencia del determinante artículo se hace innecesaria y es estructuralmente antieconómica. En efecto, estas FNs con ART+POS serían en cierta manera disfuncionales ${ }^{30}$, ya que los dos clíticos proporcionan una información excesivamente detallada y similar sobre el nominal poseído, de manera que se pierde la esquematicidad necesaria para tener aplicabilidad a una amplia gama de nominales ${ }^{3 !}$.

Por mi parte, y a la luz de nuevos datos, considero que ambas motivaciones, las semejanzas semánticas y el debilitamiento de la fuerza anafórica del posesivo arriba señalado, fueron, sin duda, parte activa de la pérdida de las construcciones del tipo la su cara, pero fue el debilitamiento del posesivo, aún más que las afinidades entre artículo y posesivo, el gran protagonista de este cambio. En el apartado que sigue intentaré explicar las causas

${ }^{29}$ Cf. J. A. Hawkins, "On (in)definite articles: Implicatures and (un)grammaticality prediction", Journal of Linguistics, 27, 1991, págs. 405-442, y Haspeimath, articulo citado en la nota 12.

${ }^{30}$ Cf. el libro de Haiman citado en la nota 12, especialmente págs. 180-181.

${ }^{31}$ La inestabilidad gramatical de FNs encabezadas por los dos clíticos parece ser una constante incluso en lenguas que mantienen este tipo de sintagmas, como si posesivo y articulo en cierta manera se rechazaran, tal es la opinión de Meier, cf. su articulo "Meu pai-0 meu pai" cjtado en la nota 14, y "Sobre expressôes de possessividade e sua historia", Boletim de Filologia, Ix, 1948, págs. 55-77; igualmente Meyer-Lübke, Grammaire, vol. III, págs. 167-168. El hecho de que estas FNS sean disfuncionales, porque aportan una precisión excesiva sobre el nominal, parece confurmarse en el hecho de que en el español medieval, en un periodo de amplio uso de ART+POS, siglo XII, son casi inexistentes los sintagmas del típo la su casa de Juan, es decir, con ART+POS y además especificadas con una FP, pero son perfectamente posibles la su casa, su casa de huan y la casa de Juan. Para algunas razones de ese rechazo y las frecuencias de uso de los cuatro tipos de FN, cf. Company, "Semántica y sintaxis de los posesivos duplicados", citado en la nota 19, en particular las págs. 130-131. Esa disfuncionalidad sería una de las causas de que sean construcciones reacias a generalizaciones, tal como sostiene el análisis tradicional. 
del debilitamiento anafórico del posesivo, que generaron un canal de gramaticalización, en el cual el posesivo se aproxima al artículo y terminan ambos clíticos por entrar en distribución complementaria.

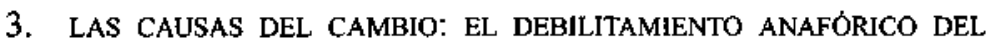 PRONOMBRE POSESIVO}

Un cambio no sintáctico, sino de naturaleza fonológica y morfofonémica, bien conocido de la diacronía del español, a saber, la invariabilidad morfológica del clítico $s u(s)$ y su falta de transparencia para referir al poseedor, consecuencia de la reducción de su étimo latino suus-sua-suum, fue, a mi modo de ver, el gran motivador inicial del debilitamiento anafórico del posesivo. Un segundo cambio sintáctico-semántico, iniciado ya en el latín mismo, consistente en la flexibilización del prọnombre posesivo en cuanto a reflexividad y anclaje referencial, ayudó a ese debilitamiento anafórico, ya que de ser un pronombre reflexivo, que entraba en serie con se, sui y sibi, y con referencia obligatoria al sujeto ${ }^{32}$, debilitó su valor reflexivo y ancló su referencia en otros constituyentes distintos del sujeto. Esa flexibilización favoreció la extensión del empleo del posesivo en las lenguas romances, pero al mismo tiempo esa extensión generó, sin duda, una buena parte de las complejidades referenciales del posesivo en el español, mismas que a su vez acarrearon una serie de cambios sintáctico-semánticos que culminan con la aproximación del posesivo a un simple presentador de sustantivos. Atenderé en este apartado a los cambios relacionados con la opacidad referencial del posesivo, motivador central, según creo, de la serie de cambios que generaron el canal de gramaticalización, y en el siguiente apartado mostraré aquellos datos del latin relacionados con la flexibilización sintáctica del posesivo que son pertinentes para mostrar ese canal de gramaticalización.

Como ya comenté, ciertos cambios fonológicos y morfofonémicos experimentados por el posesivo latino suus-sua-suum ${ }^{33}$ arrojaron en el español

\footnotetext{
${ }^{32}$ Cf. Bassols, Sintaxis latina, I, pág. 194; M. Leumann, J. B. Hofmann y A. Szantyr, Lateinische Grammatik, München, C. H. Beck, 1977, ll, págs. 174-175; O. Riemarn, Syntaxe latine, Paris, Klincsieck (septième èdition revue par A. Errout), 1886/1942, págs. 29-30. De hecho, suus era en sus origenes una forma esencialmente reflexiva y no posesiva. Gramáticas latinas clásicas, como la de Leumarn, Hoffman y Szantyr, no incluyen el análisis de suus en los apartados de pronombres posesivos (vol. I, pág. 460), sino de reflexivos (vol. l, pág. 465, y vol. [1, pág. 174). Por otra parte, la reflexividad al sujeto es el rasgo tipológico más extendido para formas reflexivas y posesivas, cf. T. Givón, Syntax. A functional typological introduction, Amsterdam: John Benjamins, 1984, esp. 353 y ss,

${ }^{33}$ Para la evolución morfológica y morfofonémica del reflexivo posesivo latino, cf., entre otros, M. Alvar y B. Pottier, Morfología histórica del español, Madrid, Gredos, 1983, esp.
} 
una forma $s u(s)$, invariable y opaca en cuanto a rasgos referenciales del poseido, con excepción del número de éste, $\mathrm{y}$, más grave aún desde el punto de vista comunicativo, totalmente opaca en cuanto a rasgos del poseedor. En efecto, la forma $s u(s)$ carga una incómoda y gran polisemia referencial ya que carece de transparencia alguna en cuanto a rasgos del poseedor, pues no indica ni el número ni el género de éste: $s u(s)$ tanto de él, de ellos, como de ella o de ellas. La reducción fonológica de $s u(s)$, junto con la pérdida de otros pronombres latinos de valor posesivo no reflexivo, eius ${ }^{34}$, fueron la clave para que iniciara el proceso de gramaticalización del pronombre posesivo, ya que aquélla produjo pérdida de información morfológica y generó un signo opaco, invariable y débil para vincular una relación posesiva. Participa esta área de la gramática del español de una característica típica de los procesos de gramaticalización, a saber, que existe una relación directa causa-efecto entre reducción fonológica $>$ opacidad $>$ gramaticalización ${ }^{35}$, y que un signo que presenta un significado más general - como sería el actual posesivo con valor de un determinante presentador- exhibe por lo regular una mayor reducción fonológica que un signo con un significado más específico ${ }^{36}$.

Diversos cambios relativamente recientes en el sistema pronominal de tratamiento del español incrementaron de manera notable la opacidad de $s u(s)$ para referir al poseedor, ya que con la creación del pronombre usted(es), el pronombre posesivo se volvió opaco también para indicar la persona del poseedor, pues debió extender su referencia a la segunda persona de cortesía, usted(es), además de la originaria y etimológica referencia de tercera persona: su(s) de él, de usted, de ellos, de ustedes. Opacidad de persona que generó, por tanto, una forma posesiva aún más polisémica. Añadido a lo anterior, la ya de por sí opaca y endeble capacidad referencial de $s u(s)$ se acentuó en el español americano, ya que éste perdió el pronombre personal de segunda persona de plural, vosotros-as, y su correspondiente adjetivo-pronombre, vuestro(s)-a(s), y debió generalizar, en consecuencia, el empleo de ustedes y $s u(s)$ como únicas formas posibles para referirse a los oyentes, desprovistas ya de valor alguno de distancia o cortesía: ustedes saben, ustedes hacen, su(s) casa(s) «de ustedes = de vosotros». La pérdida de

págs. 95-99; A. Enout, Morphologie historique du latin, Paris, Klincsieck, 1953, esp. págs. 104-105, Martínez Alcalde, Morfología histórica de los posesivos españoles, citado anteriormente, y Meyer-Lübke, Grammaire, III, págs. 392-393.

${ }^{34} \mathrm{H}$. Meier, "Sobre expressôes de possessividade e sua história", Boletim de Filologia, Ix, 1948 , págs. $55-77$, en particular la pág. 62 .

${ }^{35}$ Cf. los trabajos de Lehmann citados en tas notas 2 y 4, y Haiman, Natural syntax, cjtado en la nota 12, esp. pág. 195.

${ }^{36}$ Cf. el artículo de Bybee y Pagliuca citado en la nota 2, pág. 60; y también el capítulo 2 de Bybee, Perkins y Pagliuca, citado también en la nota 2. 
vuestro(s)-a(s) provocó una mayor frecuencia en el empleo de $s u(s)$, incrementando su carga funcional, con lo cual se intensificó en el español americano la polisemia y ambiguiedad referencial de este ya de por sí polisémico clítico ${ }^{37}$. La ambigiedad se vio favorecida además con la pérdida de la distinción de género del poseído que realizaba el adjetivo-pronombre vuestro- $a$, frente al invariable $s u(s)$. También, el mayor empleo en el español americano del uso respetuoso en singular, usted, contribuye de manera significativa al recargamiento funcional del pronombre correferencial $s u(s)$.

La persistente opacidad de $s u$, junto con el incremento de uso y mayor opacidad de este pronombre en el español americano, tuvo consecuencias directas en el debilitamiento anafórico del posesivo, y en el hecho de que son justamente los dialectos americanos, al menos algunas de sus variedades, como es el caso de la mexicana, las que llevaron, o están llevando, ese debilitamiento anafórico a sus últimas consecuencias. En efecto, son precisamente esas variedades las más innovadoras en emplear el pronombre posesivo como un simple presentador y manifestar las últimas etapas del canal de gramaticalización.

La diacronía del español no contribuyó a solucionar la opacidad del pronombre posesivo, y, comparada con otras lenguas romances, nuestra lengua no desarrolló soluciones léxico-morfológicas reales que paliaran la falta de transparencia de los rasgos referenciales del poseedor. Por ejemplo, las otras lenguas romances, además de tener concordancia de género con lo poseido $^{38}$ (it. la sua casa, il suo livro; fr. mon patron, ma patronne, port. a sua casa, o meu livro), subsanaron parcialmente la opacidad de suus, añadiendo un genitivo aclaratorio del poseedor: illorum, ${ }^{*}$ sua casa illorum ${ }^{39}$, a partir del cual se formó el pronombre posesivo de varios poseedores: it. la loro casa, fr. leur maison, occ. lor caza, cat. llur casa, rum. casa lor. El espanol, por su parte, aunque documenta en sus origenes - si bien en textos muy latinizados y de procedencia aragonesa - un pronombre posesivo re-

\footnotetext{
${ }^{37}$ Para el impacto en la sintaxis del aumento de polisemia y ambigüedad referencial del clítico posesivo, cf. C. Company, "El costo gramatical de las cortesias en el español americano. Las consecuencias sintácticas de la pérdida de vosotros", Antuario de Letras, 35, 1997, págs. 167-191.

${ }^{3 B}$ En español antiguo es posible đocumentar también variación morfológica, acorde con el género del poseído, en las formas posesivas, sua(s), sue(s), suo(s), que conviven desde los orígenes al lado del invariable $s u(s)$, particularmente en textos de adscripción regional det norte peninsular. Sin embargo, las confusiones de género en el uso de estos posesivos con variación morfológica eтал bastante frecuentes, cf. F. Hanssen, Gramática histórica de la lengua castellana, Halle, Max Niemeyer, 1913, esp. págs. 79-82, Martinez Alcalde, Morfologia histórica de los posesivos, en particular las págs. 66-67. Estas formas variables desaparecen a fines del siglo XIII.

${ }^{39}$ Cf. H. Lausberg, Lingǘtstica románica, Madrid, Gredos, 2 vols., 1965, pág. 232, y tarnbién Meyer-Lübke, Grammaire, vol. Il, págs. 128-129.
} 
flejo de illorum: lures foros ${ }^{40}$, parece haber abandonado muy tempranamente su empleo, con lo cual el pronumbre $s u(s)$ permanece hasta el espanol actual invariable y totalmente opaco para la referencia al poseedor.

La creación e integración de la forma suyo(s)-a(s) al paradigma posesivo del español fue, a mi modo de ver, de muy poca ayuda para paliar la opacidad de $s u(s)$. Las razones son varias. En primer lugar la forma suyo$a$ con valor adjetivo se documenta tardíamente en el español, siglo XIII ${ }^{41}$, cuando la reducción fonológica del posesivo reflexivo latino ya había impactado la funcionalidad de $s u(s)$. En segundo lugar, suyo siempre tuvo mala integración paradigmática: se crea sobre un modelo, cuyo ${ }^{42}$, de muy baja productividad y mal instalado en el sistema, con francos competidores desde el iberorromance temprano ${ }^{43}$; al igual que su modelo, suyo es también de muy baja frecuencia en el español ${ }^{44}$. En tercer lugar, y lo más importante, la forma suyo, no obstante que exhibe más morfología que $s u(s)$ para informar de los rasgos léxicos del poseído, suyo(s)-a(s), sigue siendo igual de opaca que aquel para referir al poseedor. Los ejemplos de (8) muestran que, dada esa opacidad referencial, suyo entra en el mismo tipo de distribuciones sintácticas desambiguadoras sobreespecificadas que $s u(s)$.

(8) Tan bien los prinçipes de los otros linages como los suyos dell e tod el otro pueblo (GEII, 6.27b).

E de la otra parte sallieron a conseio e acordaron que pues cavallero por el rey fablara que fablasse por la suya dellos cavallero e non ninguno dellos (Pedro I, 62.54b).

Aventurando su vida por salvar la suya del emperador (Amadis). Un hermano suyo que tenía (Patrañuelo) ${ }^{45}$.

La serie de causas parciales que acabamos de plantear y que constituyen la compleja motivación inicial del canal de gramaticalización aparece resumida en (9):

\footnotetext{
${ }^{40}$ Cf. R. Menéndez Pidal, Origenes del español. Estado lingüistico de la Peninsula lbérica hasta el siglo XI, Madrid, Espasa Calpe, 1926/1950, pág. 346.

${ }^{41}$ Cf. J. Comu, "Le possessif en ancien espagnol", Romania, XII, 1884, págs. 307-314, en particular la pág. 310.

${ }^{42}$ Cf. Alvar y Pottier, Morfología histórica del español, pág. 99 y también Cornu, citado en la nota anterior, pág. 313.

${ }^{43}$ Cf. A. Tsutsumi, "Posesivos relativos estigmatizados: ctyo vs. que su en la evolución del español", Actas del v Congreso Internacional de Historia de la Lengua Española, en prensa.

${ }^{44}$ Cf. C. Company, La frase sustantiva, citado en la nota 10 , cap. 2.

${ }^{45}$ Este ejemplo y el anterior del Amadis provienen de Meyer-Lübke, Grammaire, vol. III, pág. 93.
} 
(9) CAusas parciales iniciales de la gramaticalización del posesiVO COMO DETERMINANTE

(a) Un cambio fonológico: reducción fonológica y morfológica de sutus-sua-suum produce una forma invariable $s u(s)$.

(b) Un cambio sintáctico semántico: flexibilización de suus en reflexividad y anclaje referencial: no sólo al sujeto.

(c) Opacidad de $s u(s)$ para género y número del poseedor.

(d) Incremento de opacidad a persona del poseedor, $3 \mathrm{a}+2 \mathrm{a}$, por desarrollo de pronombre de respeto usted(es).

(e) Incremento de opacidad y recarga funcional de $s u(s)$ en el español americano por pérdida de vosotros-vuestro y uso obligatorio de ustedes y $s u(s)$.

(f) No desarrollo de soluciones léxico-morfológicas reflejos de illorum.

(g) No ayudó la creación de suyo: documentación tardía, mala integración paradigmática, baja frecuencia y opaco al poseedor.

Aunque el español no desarrolló soluciones morfológicas, sí buscó soluciones sintácticas para hacer explícita la referencia al poseedor, pero, paradójicamente, algunas de esas soluciones fueron las causantes principales del debilitamiento de la fuerza anafórica del posesivo y de su aproximación al artículo. La necesidad de aclarar la referencia al poseedor es el hilo conductor que cohesiona todas las soluciones que veremos y las respectivas construcciones involucradas. Ello se debe a que el poseedor es la entidad más prominente de la relación posesiva, que se caracteriza por ser altamente topical y persistente discursivamente, esto es, mantiene su referencia en el contexto aun cuando pueda parecer innecesaria ${ }^{46}$; es también la entidad que controla al poseído, determina la ubicación de éste en su dominio, es-

46 Es bastante frecuente documentar empleos de $s u(s)$ que parecen un tanto innecesarios, bien porque es obvia la relación posesiva, primer ejemplo, o bien porque se muestra como una relación posesiva débil, en donde es totalmente prescindible el posesivo, segundo y siguientes ejemplos: "El 27 fallecio a los 63 años de su edad la señora Doña Maria Anna Gomez de Cervantes" (Gazeta de México, 1734, 78, pág. 1619), "El 17 fallecio a los 65 años de su edad el R. P. Fr. Nicolas de Quiñones" (Gazeta de México, 1736, 95, pág. 756); este uso posesivo es una fómula constante empleada en los obituarios de los primeros periódicos de México a lo largo del siglo XVII]. "E levavan poder del rey don Pedro para lo desposar con ella por palabras de presente e otrossi por fazer sus ligas e amistades con el dicho rei de Françia" (Pedro 1, 27, 42b), "E enbio el rey por sus enbaxadores a don Iohan Sanchez de las Roelas... e a don Alvar Garçia de Albornoz" (Pedro [, 27, 32b), "D. Juan Fernandez de Oraz y D. Manuel Rodriguez Pedrozo, quienes, arteglandose a las ordenes de S. Exc. Ilma. saldran a su tiempo de esta capital para el pueblo de Xalapa" (Gazeta de México, 1736, 100, pág. 795). Parece claro que estos posesivos "innecesarios" están motivados por el deseo de otorgarle persistencia referencial discursiva al poseedor. 
tablece los rasgos léxicos de la FN poseída que puede entrar en relación con él y decide la interpretación de la construcción posesiva en su totalidad ${ }^{4}$. La incapacidad de $s u(s)$ para significar al poseedor motivó profundos reajustes en esta zona de la gramática del español.

Veamos las soluciones sintácticas que aminoran la opacidad e incómoda polisemia referencial de $s u(s)$. Veamos también las problemáticas consecuencias diacrónicas que acarrearon algunas de esas soluciones. Es un vaivén permanente de soluciones que, a su vez, acarrean problemas.

Solución (1): Anclaje referencial de distancia mínima. El uso normal y no marcado del pronombre posesivo en el español es con referencia anafórica al poseedor, reflejo directo del latín, y en contextos donde el poseedor aparece explícito y muy próximo al posesivo (10). El poseedor puede manifestarse ya sea léxicamente (10a), ya mediante un clítico (10b), o incluso un morfema verbal de persona, indicador del poseedor expresado con anterioridad (10c), permite aclarar la referencia de $s u(s)$. Por tanto, esta alta cohesión textual referencial, a la que he denominado "deixis de distancia mínima» ${ }^{48}$, ancla sin ambigüedades la mayoria de las veces la referencia al poseedor, y resuelve en buena medida la opacidad referencial de $s u(s)$, opacidad provocada, como ya comentamos, por la escasa estructura morfológica de este pronombre.

(10) (a) Pero después $e l l a_{\mathrm{i}}$ de $s u_{\mathrm{i}}$ voluntad sallio del monesterio (Pedro I, 89.23a).

Llegate aca, putico, que no sabes nada del mundo $o_{\mathrm{i}}$ ni de su$s_{\mathrm{i}}$ deleites (Celestina, I.43.129).

(b) Porque $l a s_{\mathrm{i}}$ he visto que sus $s_{\mathrm{i}}$ cuerpos parecen torres iguales (Lozana, M. XVIII.258).

(c) Que tiene $e_{\mathrm{i}}$ dicho la verdad e $a_{\mathrm{i}}$ confesado $s u_{\mathrm{i}}$ pecado y que en ello se ratifica (AGN, H.162v).

\footnotetext{
${ }^{47}$ Para la relevancia del poseedor y el control de éste sobre el poseído, cf., entre otros, Ch. Barker, "Definite possessives and discourse novelty", Chicago Linguistics Society, 28, 1992, págs. 26-41; C. Company, "Semántica y sintaxis", citado anteriormente, Heine, Possession, cap. 1; Langacker, "Reference-point constructions", Cognitive Linguistics, 4, 1993, y "Possession and possessive constructions, Language and the cognitive construal of the world, J. R. Taylor y R. E. Mc Laury eds., Berlin-New York, Mouton de Gruyter, !995, págs. 5!-79; H. Seiler, Possession as an operztional dimension of language, Tübingen, Gunter Narr, 1983, y M. Velázquez, The grammar of possession. Inalienability, incorporation and possessor ascension in Guarani, Amsterdam, John Benjanins, 1996, esp. cap. 2. Una prueba de que el poseedor decide la interpretación de la construcción posesiva en su totalidad se puede observar en FNs con coordinación de los nominales poseídos, en casos como: "El declarante contestó que ahí vive su familia y dos más, por lo cual no conoce a la persona que se le indica". En este ejemplo, es el poseedor, declarante, y no el poseido, familia, el nominal que liga la referencia del sintagma cuantificado dos más, por lo cual se le otorga la lectura "y dos personas más" y no "dos familias más".

${ }^{48}$ Cf. Company, "Old forms for new concepts", citado en la nota 20 , pág. 77.
} 
Problema (la): Empleos catafóricos. Junto al uso normal anafórico del posesivo, es posible documentar en el español empleos catafóricos, en los que el pronombre posesivo ancla su referencia al poseedor fuera de su $\mathrm{FN}$ pero en el contexto que sigue y no en el que precede, si bien manteniendo, al igual que en los empleos anafóricos, una distancia textual mínima entre poseído y poseedor (11). Tales usos catafóricos, esporádicos en el español antiguo y algo más frecuentes en el español americano actual, como muestra el cuadro 2 de más abajo, suponen en sí mismos un debilitamiento del estatus del posesivo como pronombre anafórico, ya que lo convierten en catáfora. Como veremos, este ligero aumento, de $2 \%$ a $8 \%$, que considerado de manera aislada podría parecer no significativo, dada su baja frecuencia general, va en la misma dirección de los otros cambios y apoya el debilitamiento general del posesivo como anáfora.

(11) Aquel atento escuchar de Celestina da materia de alargar en $s u_{\mathrm{i}} \mathrm{ra}$ zon a nuestro amo $o_{\mathrm{i}}$ (Celestina, VI.116.63).

$\mathrm{Y}$ estando en $s u_{\mathrm{i}}$ casa esta declarante el $_{\mathrm{i}}$ viernes en la noche, serían como a las ocho (DLNE, 1686, 139.367).

El 28 se comenzó novenario en $s u_{\mathrm{i}}$ santuario a la milagrosa ima-

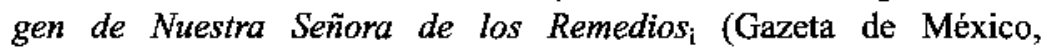
año 1734 , No. 78 , p. 619).

El 12 celebró con grande magnificencia $s u_{\mathrm{i}}$ fiesta titular, en el Convento Grande de Nuestra Señora de la Merced, la ilustre archicofradia de la Concepción $_{\mathrm{i}}$ (Gazeta de México, año 1736, No. 97, p. 771).

Aportaciones voluntarias de sus alumnos a la Universidad Nacional Autónoma de México 1998 (español actual de México, titular de un periódico).

Cuadro 2

INCREMENTO DE EMPLEOS CATAFÓRICOS DE SU(S)

(conteos realizados sobre $1.000 \mathrm{FNS}$ introducidas por $s u(s)$ )

(no se consideran FNS con doblamiento del poseedor del tipo su casa de Juan)

\begin{tabular}{ll}
\hline SIGLOS XV-XV] & $2 \%(23 / 1.000)$ \\
SIGLO $x \mathrm{XX}$ & $8 \%(82 / 1.000)$ \\
\hline
\end{tabular}

Problema (1b): Casos de vaguedad y ambigüedad referencial. A pesar de la cohesión textual de deixis mínima entre poseído y poseedor arriba señalada, existen en todas las etapas del español bastantes usos de FNs posesivas en que es muy dificil, casi imposible, establecer con recursos lingüisticos la re- 
ferencia al poseedor (12), ya que queda totalmente ambiguo el posible verdadero poseedor de la entidad poseída, pues aparecen en un mismo contexto próximo varios sustantivos capaces de constituirse en poseedores de la entidad poseída (12a), conflicto de poseedores que se mantiene con frecuencia aún en FNs posesivas altamente especificadas (12b). Así, en los ejemplos de (12a) y (12b) cualquiera de los sustantivos o pronombres nombrados antes o al interior de la FN posesiva: Pero Alvarez o Diego García y cualquiera de los referentes de él en (12a), el sujeto de demandó o el ydolo del sol, ellos o él en (12b), podrian ser los poseedores de la entidad poseída, núcleo de la $\mathrm{FN}$ posesiva. En numerosas ocasiones, estos contextos con varios posibles poseedores sólo se desambiguan por conocimiento de mundo o por conocimiento del texto narrativo (12c). Así, en el primer ejemplo de (12c) se sabe por un conocimiento pragmático que son los humanos, y no las entidades inanimadas, los que más fácilmente se constituyen en poseedores en la mayoria de culturas $^{49}$, de ahi que se le asigne la referencia de poseedor al segundo $o$ al tercer sustantivo, filósofos, poetas, o a ambos a la vez, pero no al primero, istoriales. Igualmente, en el segundo ejemplo de (12c) la lectura inmediata de anclaje referencial es con Dios como poseedor y no con el pronombre pocos, no obstante que éste cumple mejor el requisito de deixis de distancia mínima, asignación referencial que viene dada por cuestiones pragmáticas: el primer nominal ocupa una posición jerárquica superior en nuestra cultura. Coincide plenamente el español en este recurso pragmático de desambiguación con muchas lenguas, ya que parece ser una caracteristica tipológica de la posesión nominal que sean aspectos pragmáticos y específicos de una cultura los que determinen muchas veces quién es el poseedor y cuál es el tipo de relación semántica posesiva que se establece entre poseedor y poseído ${ }^{50}$.

(12) (a) E Pero Alvarez de Osorio ${ }_{\mathrm{i}}$ comia ese dia con Diego García ${ }_{\mathrm{j}}$, maestre de Calatrava, en $s u_{\text {ij }}$ posada, e era en quaresma (Pedro I, 112.42b).

Quando el cavallero ançiano oyó esta razón, entendióla muy bien; et otrosí, conosçió que aquél era Saladín; ca él $l_{i}$ visquiera muy grand tiempo con $e \dot{e} l_{j}$ en $s u_{i j}$ ? casa (Lucanor, L.249).

(b) Et otro dia demando $o_{\mathrm{i}}$ al ydolo del sol $l_{\mathrm{j}}$ por sus ij? $_{\mathrm{ij}}$ suertes que farie (GEIl, 60,11b).

Et ellos dixeronle que eso mesmo fallaran ellos $s_{\mathrm{i}}$ en sus $_{\mathrm{ij}\}}$ escripturas que é $l_{\mathrm{j}}$ avia fallado (Calila, 100).

\footnotetext{
${ }^{49}$ Cf. Seiler, Possession, y Company, "Semántica y sintaxis", citado en la nota 19.

${ }^{50}$ Cf. Barker, "Definite possessives", citado en la nota 46, esp. pág. 30; Heine, Possession, citado en la nota 22, cap. 1, y Seiler, Possession, citado en la nota 47 , pág. 3.
} 
(c) Lee los istoriales, estudia los filosofos, mira los poetas $\mathrm{j}_{\mathrm{j}}$. Llenos están los libros de sus $s_{\mathrm{ij} \text { ? }}$ viles y malos enxemplos (Celestina, I.25.43).

Muchos nombran a Dios $_{\mathrm{i}}$ et fablan en l', et $\operatorname{pocos}_{\mathrm{j}}$ andan por los libros de las sus $\mathrm{ij}_{\mathrm{ij}}$ carreras (Lucanor, 269).

Solución (2): Especificación del poseedor en su misma FN. Ante los problemas comunicativos, las lenguas suelen buscar soluciones que logren éxito comunicativo. Un recurso constante de la sintaxis del español para desambiguar la polisemia de $s u(s)$ es hacer mención al poseedor dentro de la misma FN poseída (13), bien con una FP adnominal que contiene léxicamente al poseedor (13a), bien con una oración de relativo especificativa (13b), que contiene una mención al poseedor, ya sea de manera léxica, ya mediante un clítico, ya mediante la morfología verbal de persona. Estas FNS de doble referencia al poseedor muestran, siempre un orden fijo de las entidades que contraen la relación posesiva: poseído antecede-poseedor sigue, siempre establecen una relación binaria en donde los dos indicadores de la relación posesiva, pronombre posesivo y poseedor, son correferenciales y se sitúan dentro de un mismo constituyente, y siempre son, en consecuencia, altamente especificadas.

Las FNs posesivas con doble referencia al poseedor convierten automáticamente al posesivo en una catáfora endocéntrica, endocéntrica en el sentido de que el pronombre no tiene que buscar su anclaje referencial fuera de su $\mathrm{FN}$, tal como lo haría una anáfora típica. Estas FNs posesivas con doble referencia al poseedor, ya sea mediante FP adnominal, ya sea con oración de relativo, eran escasas en el español medieval, aumenta su empleo en el español novohispano del siglo XVI, y están extendiendo su uso de manera interesante en el español actual de México, como muestra el cuadro 3 de abajo para las construcciones del tipo su casa de Juan (contrastadas con FNs encabezadas por artículo, la casa de Juan) ${ }^{51}$. El aumento en la frecuencia de uso, como veremos, está en relación directa con el debilitamiento anafórico de $s u(s)$ y con la consecuente aproximación funcional de esta forma a un simple determinante, casi desprovisto de significado posesivo.

\footnotetext{
${ }^{5}$ En el español americano mexicano, estas fNs sobreespecificadas de débil valor posesivo desarrollaron valores pragmáticos especiales, próximos al de posesión inalienable, cf. Company, "Cantidad vs. cualidad en el contacto de lenguas", citado en la nota 19. Coincide este debilitamiento del posesivo y su nuevo valor semántico con el rasgo extendido tipológicamente de que la posesión inalienable no suele marcarse con marcas posesivas en la mayoría de lenguas del mundo, cf., entre otros, J. Haiman, "Iconic and economic motivation", Language, 59, 4, 1983, págs. 781-819, especialmente pág. 805; Heine, Possession, cap. 2, y Velázquez, The grammar of possession, caps. 2 y 4 . Por lo que respecta al español, se marca con un posesivo débil, poco posesivo.
} 
(13) (a) $Y$ que lo enterrasen como gran rey que era, y que alzasen a su primo del Montezuma, que con nosotros estaba, por rey (Bernal, CXXVII, 378).

Señor, no, sino que soy venida aqui, que su nuera d'esta señora está de parto, y querria hacer, como eche las pares, me las vendan (Lozana, XXIV, 293).

(b) Desi mando tornar al lobo a su estado et en su dignidat que ante avia et al ofiçio en que era puesto (Calila, 315).

El paquete que les había preparado tenía sus dobladas que tanto le gustan a Pedro (español de México, habla espontánea popular, dobladas $=$ un tipo de comida).

CUADRO 3

INCREMENTO DE FNS CON DOBLAMIENTO DE POSEEDOR

\begin{tabular}{ll}
\hline & POS $+\mathrm{N}+\mathrm{DE}+\mathrm{N}$ \\
\hline SIGLO XIII & $6 \%(89 / 1.520)$ \\
SIGLOS XV-XVI & $8 \%(153 / 1.850)$ \\
SIGLO $x \mathrm{X}$ & $11 \%(169 / 1.576)$ \\
\hline
\end{tabular}

La aclaración del poseedor dentro de su misma FN posesiva fue sin duda una buena solución sintáctica a la polisemia y opacidad referencial de $s u(s)$. En efecto, en los ejemplos de (14) si no se especifica el poseedor dentro de su misma FN posesiva, se podría interpretar que la entidad poseída pertenece a otro poseedor (14a-c) o sería imposible saber quién es el poseedor (14d). Si en esas FNs no se pospone el poseedor, el mensaje comunicado sería erróneo o vago, bien porque se activaría el principio de anclaje referencial de distancia mínima y se le asignaría la posesión a otro poseedor: aquella señona y no Celestina en (14a), el oyente o receptor de la carta y no Delgadillo en (14b), o bien porque quedaría ambiguo quién es el verdadero poseedor: en (14c) tanto los marineros como el sujeto de cantar podrían ser los poseedores de la farpa, o bien (14d), porque quedaría en total vaguedad quién es el poseedor de dos entidades poseídas padre y ca$s a$. Por lo tanto, en todos los ejemplos de (14) la presencia pospuesta del poseedor es gramaticalmente necesaria, está plenamente justificada y soluciona sintácticamente la opacidad referencial del pronombre posesivo. No se trata, por tanto, de construcciones pleonásticas o redundantes, como tradicionalmente se las ha clasificado, sino que tienen plena funcionalidad comunicativa. 
(14) (a) Nunca te oi dezir mejor cosa. Mucha sospecha me pone el presto conceder de aquella señora y venir tan aina en todo su querer de Celestina (Celestina, XI.192.21).

(b) Y soy jnformado y muy çertificado que su hermano de Delgadillo, que embiaron a Guaxaca por justicia mayor, las llevó a cuestas de jndios a su jurisdicion (DLNE, 1529, 7.71).

(c) Rogo mucho a los marineros quel dexassen antes cantar con la su farpa que traye (GEII, 185.9a).

(d) Llegamos al cuerpo de la ciudad, donde nos habiamos de aposentar, que era una casa grande que habia sido de su padre de Guanacasin, señor de la dicha ciudad (Cortés, $3^{a}{ }^{a}$ carta, 123).

Problema (2): Debilitamiento anafórico del posesivo. La solución expuesta arriba acarreó, sin embargo, un prọblema: un clato debilitamiento del valor anafórico del pronombre posesivo, ya que éste, en esos sintagmas posesivos con doble referencia al poseedor, ancla su referencia dentro de su propia $\mathrm{FN}, \mathrm{y}$ hace innecesaria, por lo tanto, la búsqueda de anclaje referencial fuera de la $\mathrm{FN}$ posesiva, búsqueda externa que define gramaticalmente a los pronombres anafóricos en muchas lenguas del mundo ${ }^{52}$. La necesidad de aclarar el poseedor dentro de la $\mathrm{FN}$ posesiva provocó un cambio en la naturaleza del pronombre posesivo, cambio que se puede resumir como un progresivo debilitamiento de la fuerza anafórica del posesivo. Este debilitamiento anafórico permitió al posesivo ampliar su capacidad sintáctica (15), de tal manera que en los dialectos más innovadores $s u(s)$ puede encabezar FNs en posiciones iniciales absolutas o casi iniciales, en las que el poseedor aparece nombrado por primera vez dentro de su propia FN (15a), y puede concurrir en contextos donde parecería totalmente "innecesario" el empleo del posesivo o bien el de la FP adnominal o el de la oración relativa, ya que ese mismo poseedor ha sido nombrado antes (15b), contextos donde, en otras variedades, por ejemplo en el español peninsular, se emplearía artículo o se evitaría la especificación.

Es decir, el doblamiento del poseedor inició en el español antiguo, como muestran los ejemplos de (13) y (14), como una solución para identificar textualmente el verdadero poseedor de una entidad poseída, pero esas FNs, justamente por la inclusión del poseedor dentro de ellas, debilitaron la capacidad anafórica del posesivo, de tal manera que éste pudo deslizarse a contextos que no presentaban conflicto textual entre varios poseedores, como son los de (15). El posesivo que encabeza estas FNs está, en conse-

${ }^{52}$ Cf. T. Givón, Functionalism and grammar, citado en la nota 15, pág. 247. 
cuencia, ya muy próximo a un artículo, un simple presentador de la FN. El aspecto de estas FNS es que son formalmente muy "posesivas", pero en realidad en ellas el posesivo tiene muy poco valor posesivo, ya que está imposibilitado, o muy debilitado, de anclar anafóricamente a su poseedor.

(15) (a) Su precio comercial de esta bonita agenda es de veinte pesos (español de México, habla popular, vendedor voceando el producto, siempre repite la misma FN).

¿Qué crees, mamá? Que en su casa de Claudia comen el pozole con aguacate (español de México, habla popular).

Debido a su trabajo que ha desempeñado, Hugo Sánchez merece estar en la Selección (español de México, habla culta, programa de TV).

(b) He andado hasta por Guerrero buscando si lo fueron a aventar por ahí. Su ropa que llevaba no se me olvida (español de México, périódico El Financiero).

Rivas no tiene mucho afecto por el teatro francés, a pesar de su conocimiento que tiene sobre el tema (español de México, habla culta, registro conferencia).

Ya me dio el nombre de su programa de cómputo que usa él (español de México, habla culta).

Se conserva bien Lety ino crees?, es muy linda, y aunque su hijo de ella ha crecido mucho, ella todavía parece su hermana (español de México, habla culta).

La flexibilización distribucional del posesivo reflejada en los ejemplos anteriores muestra que $s u(s)$ añadió a su originario valor pronominal anafórico, un nuevo valor más general y abstracto, próximo a un peculiar artículo, vía el progresivo debilitamiento de su valor etimológico. Se trata de un presentador que se emplea para introducir nominales que establecen una relación especial con el poseedor pospuesto ${ }^{53}$. El cambio puede resumirse como un reanálisis del pronombre posesivo: ANÁFORA > DETERMlNANTE, con ambos valores, el conservador anafórico y el innovador determinante, conviviendo, con diferente manifestación cuantitativa, en varias de las etapas de la evolución del español. El cambio aparece esquematizado en (16). Las etiquetas de la derecha caracterizarian a un posesivo en cualquier estado de lengua anterior al representado por las etiquetas de la derecha.

${ }^{53}$ Cf. Company, "Cantidad" y "Old forms", y Reyes, Posesivos y relativas especificativas, citados en la nota 20. 
(16) DEBILITAMIENTO ANAFÓRICO Y REANALISIS DEL PRON. POSESIVO

$\begin{array}{ll}\text { fuerte anclaje referencial } & \rightarrow \text { débil anclaje referencial } \\ \text { anclaje externo a su FN } & \rightarrow \text { anclaje interno a su FN } \\ \text { anáfora exocéntrica } & \rightarrow \text { catáfora endocéntrica } \\ \text { pronombre anafórico } & \rightarrow \text { presentador, determinante }\end{array}$

En los cuadros que siguen se puede observar las frecuencias relativas de uso que apoyan el progresivo debilitamiento anafórico del posesivo y su deslizamiento hacia una función de determinante, presentador de la FN. En el cuadro 4 se observa un notable incremento de FNs con doblamiento de poseedor, del tipo su casa de Juan, no motivadas por ambigüedad textual entre varios posibles poseedores, de $36 \%$ a $78 \%$. El cuadro 5 muestra un aumento muy importante de esas FNs en posición inicial, de $5 \%$ a $33 \%$, donde el posesivo está imposibilitado de anclaje anafórico. Finalmente, el cuadro $6^{54}$ muestra que las FNs encabezadas por posesivo y con una oración relativa especificativa que contiene a un poseedor correferencial empiezan a ser frecuentes en el español actual de México, $24 \%$, pero tienen muy baja, casi nula, productividad en el español peninsular, 1\%. Todos los cambios apuntan hacia un incremento en el empleo de posesivos no anafóricos, aumento que es señal de la progresiva obligatoriedad $y$, por lo tanto, de la gramaticalización de su como DET.

Cuadro 4

INCREMENTO DE FNS CON DOBLAMIENTO DE POSEEDOR SIN AMBIGOEDAD ENTRE VARIOS POSEEDORES

\begin{tabular}{lll} 
& + AMBIGÜEDAD & - AMBIGÜEDAD \\
\hline SIGLOS xV-XVI & $64 \%(98 / 153)$ & $36 \%(55 / 153)$ \\
SIGLO $\mathrm{xx}$ & $22 \%(38 / 169)$ & $78 \%(131 / 169)$ \\
\hline
\end{tabular}

CUADRO 5

INCREMENTO DE FNS CON DOBLAMIENTO DE POSEEDOR

EN POSICIÓN INICIAL ABSOLUTA

\begin{tabular}{ll}
\hline SIGLOS XV-XVI & $5 \%(7 / 153)$ \\
SIGLO XX & $33 \%(55 / 169)$ \\
\hline
\end{tabular}

54 Apud Reyes, Posesivos y relativas especificativas, citado en la nota 19. 
CUAARO 6

PRODUCTIVIDAD DE FNS CON ORACIÓN RELATIVA ESPECIFICATIVA INTRODUCIDAS POR ARTÍCULO VS. POSESIVO

\begin{tabular}{lll}
\hline & ARTÍCULO & POSESIVO \\
\hline ESP. MEXICANO & $76 \%(514 / 680)$ & $24 \%(166 / 680)$ \\
ESP. PENINSULAR & $99 \%([53 / 155)$ & $1 \%(2 / 153)$ \\
\hline
\end{tabular}

\section{4. el CaNAl de gramatiCalización. las etapas del Cambio}

Un examen cuidadoso de los cambios numerados en (2) y analizados cualitativa y cuantitativamente en el apartado anterior, aunque a primera vista desconectados, sugiere que debieron entablar entre sí una relación diacrónica en cadena, un canal de gramaticalización, donde algunos de ellos son la consecuencia de otros previos. Consideradas las construcciones posesivas involucradas en esos cambios bajo una perspectiva dinámica (17), creo que, como ya señalé, todas ellas surgieron como soluciones a la total opacidad referencial del pronombre posesivo, pero acarrearon, paradójicamente, un decidido debilitamiento dé́ctico anafórico del pronombre posesivo. Debilitamiento anafórico que provocó la actual distribución complementaria de artículo y posesivo y, en consecuencia, la ampliación de la clase DET en el español mediante la inclusión del posesivo. Los dialectos más innovadores, en este caso algunas variedades hispanohablantes americanas, muestran las últimas etapas del canal de gramaticalización, con usos de posesivos muy próximos a simples determinantes, tal como indican los cuadros 4-6 del apartado anterior.

La forma innovadora, esto es, el pronombre posesivo paulatinamente desprovisto de su fuerza anafórica y cada vez más próximo a un determinante, avanzó, como es usual en los procesos de cambio lingüístico, a contextos cada vez más propicios y motivadores para el debilitamiento anafórico del posesivo. Una motivación económica, la afinidad semántica de posesivo y artículo ya comentada, coadyuvó sin duda a que artículo y posesivo se excluyeran, dejando libre el camino, el espacio gramatical, para que el posesivo se aproximara al artículo, vía el debilitamiento de las propiedades anafóricas de aquél.

Las diversas etapas del canal suponen en sí mismas cambios distintos pero no constituyen cambios cumplidos ni estados de lengua cerrados, sino que, vistas en sus relaciones, sugieren un proceso global histórico, como un continuum diacrónico manifestado en una cronología relativa de cambios, 
con varios estados de lengua que se superponen y conviven a lo largo de la evolución sintáctica del español, superposición y convivencia que se mantiene en la mayoria de las actuales variedades hispanohablantes, mayoria constituida en este caso por los dialectos americanos ${ }^{55}$. En efecto, en muchos dialectos del español conviven los usos etimológicos anafóricos "ortodoxos" del pronombre posesivo con usos innovadores de posesivos próximos a artículos. Los números secuenciales de (17) indican las etapas, estados de lengua o fases del proceso global de gramaticalización, donde 1) representa el estado de lengua inicial, correspondiente al latín clásico. Los números de los ejemplos reproducen el número de la etapa diacrónica relativa del fenómeno, y, para comodidad del lector, se repiten en su mayoria los ejemplos ya dados.

(17) CANAL DE GRAMATICALIZACIÓN DEL PRONOMBRE POSESIVO SU(S)

1) Anáfora reflexiva correferencial al sujeto: suus es un pronombre reflexivo anafórico dirigido obligatoriamente al sujeto; su carácter posesivo era secundario.

(1) Caesar suas $_{\mathrm{i}}$ copias subducit (BG, i.22) ${ }^{56}$.

Appius Claudius, aestu suo Locros traiecit (Liv.) $^{57}$.

2) Flexibilización sintáctica: suus es un pronombre anafórico posesivo que flexibiliza su anclaje referencial: no necesariamente al sujeto, y debilita su valor reflexivo. La flexibilización sintáctica se debió bien a que ancla su referencia en otro argumento, por ejemplo el objeto (2a), o bien a que suus aparece en una oración subordinada cuyo sujeto es vago o sólo está implícito (2b). El latín tenía empleos no correferenciales del posesivo (2c), heredados por el español (2d).

(2) (a) Suis flammis delete Fidenas $_{\mathrm{i}}$ (Liv., iv.33) ${ }^{58}$. Si quidem hanc $\mathrm{c}_{\mathrm{i}}$ vendidero pretio suo $_{\mathrm{i}}$ (Plaut.) ${ }^{59}$.

\footnotetext{
${ }^{55}$ Los mismos empleos se pueden documentar en otras variedades americanas, por ejemplo en Venezuela, Perú y Costa Rica, of. Company, "Cantidad vs. cualidad", Ch. Kany, Sintaxis hispanoamericana, Madrid, Gredos, 1969, y J. A. Rodríguez Garrido, "Sobre el uso del posesivo redundante en el español de Perú", Lexis, 6, 1982, págs. 117-123.

S6 Apud Allen y Greenough, New Latin grammar for schools and colleges founded on comparative grammar, J. B. Greenough, G. L. Kittredge, A. A. Howard y B. L. D'ooge eds., New Rochelle-New York, Caratzas Brothers Publishers, 1904/1979, pág. 180.

${ }^{57}$ Apud Bassols, Sintaxis latina, vol. I, pág. 193.

${ }_{58}$ Apud Allen y Greenough, New Latín grammar, pág. 182.

${ }^{59}$ Apud Leumann, Hofmann y Szantyr, Lateinische Grammatik, vol. If, pág. 103.
} 
(b) Meritis suis gratias referre volui (CIL) ${ }^{60}$.

(c) Suo gaudete munere Manes (suo $=$ uvestro», CE) $^{61}$.

(d) Tenemos su poco de miedo ${ }^{62}$.

3) Simplificación morfológica y opacidad referencial. Pérdida de marcas morfológicas, que crea una forma invariable $s u(s)$, totalmente opaca para la referencia del poseedor, que genera ambigüedad y polisemia. Solución $=$ Pronombre anafórico exocéntrico con anclaje referencial de distancia deíctica mínima (3a). Persisten las dificultades para la identificación del poseedor (3b).

(3) (a) Pero después ella de $s u_{\mathrm{i}}$ voluntad sallio del monesterio (Pedro I, 89.23a).

Llegate aca, putico, que no sabes nada del mundo $o_{\mathrm{i}}$ ni de sus $_{\mathrm{i}}$ deleites (Celestina, I.43.129).

(b) E Pero Alvarez de Osorio ${ }_{\mathrm{i}}$ comia ese dia con Diego Garcia $\mathrm{j}_{\mathrm{j}}$ maestre de Calatrava en $s u_{\mathrm{ij} \text { ? }}$ posada (Pedro I, 112.42b).

4) Catáfora endocéntrica por ambigüedad textual. Se documentan FNS posesivas con el poseedor pospuesto dentro de la misma FN. Catáfora endocéntrica motivada textualmente por la necesidad de identificar al poseedor $=$ Debilitamiento del significado deíctico anafórico originario $=$ Comienza a excluirse con el artículo.

(4) Nunca te oi dezir mejor cosa. Mucha sospecha me pone el presto conceder de aquella señora, y venir tan aina en todo su querer de Celestina (Celestina, XI.192.21).

Rogo mucho a los marineros quel dexassen antes cantar con la su farpa que traye (GEII 185.9a).

5) Exclusión de artículo y posesivo en una misma $F N=$ Distribución complementaria de artículo y posesivo en el español general. Permanece residualmente en algunas variedades.

(5) ART+POS+N: la su casa $\rightarrow \varnothing$

6) Catáfora endocéntrica sin ambigüedad textual. Incremento del debilitamiento anafórico del posesivo. FNs posesivas de doble referencia al poseedor

\footnotetext{
60. Apud Bassols, Sintaxis, vol. I, pág. 192.

61 Apud Bassols, Sintaxis, vol. I, pág. 194.

62 Citado en Meyer-Lübke, Grammaire, vol. [1, pág. 79.
} 
no motivadas textualmente por conflicto de poseedores. Aparición en contextos iniciales absolutos y en contextos "innecesarios". Extensión de empleo de esas FNS $=$ Posesivo es un presentador de frase, sin fuerza anafórica posesiva $=$ Muy próximo a un artículo.

(6) Su precio comercial de esta bonita agenda es de veinte pesos. Debido a su trabajo que ha desempeñado. Hugo Sánchez merece estar en la Selección.

Rivas no tiene mucho afecto por el teatro francés, a pesar de $s u$ conocimiento que tiene sobre el tema.

7) Incremento de usos catafóricos con anclaje externo a la FN posesiva.

(7) Como es una cirugía mutilante y les quitan su matriz y sus ovarios a las mujeres con cáncer, entonces hay que administrar más hormonas, más estrógenos (español de México, programa de radio).

Si dinamizamos en forma de esquema la cronologia de cambios arriba propuesta (18), se nos muestra un canal de gramaticalización, a través del cual el originario posesivo latino terminó aproximándose a un artículo. El estado de lengua representado más a la derecha constituye la fase inicial del proceso, y el estado de lengua más a la izquierda es la fase más innovadora, representada por algunos dialectos del español americano. En esta última etapa el posesivo ha debilitado su capacidad anafórica y se comporta como un simple y peculiar determinante. Varias de las etapas, como dije, conviven en un mismo estado de lengua.

\section{(18) CANAL DE GRAMATICALIZACIÓN DE $S U(S)$ EN ESQUema}

Anáfora reflexiva con anclaje obligatorio al sujeto $>$ anáfora no reflexiva con anclaje a argumentos no sujeto $>$ simplificación morfológica y opacidad referencial de $s u(s)>$ anáfora exocéntrica $>$ catáfora endocéntrica e inicio de debilitamiento anafórico del pronombre $>$ distribución complementaria de artículo y posesivo $>$ incremento de debilitamiento anafórico $>$ posesivo como determinante $>$ incremento de usos catafóricos.

Las diferentes etapas del canal arriba representadas pueden ser consideradas como un continuum semántico evolutivo en el que en cada etapa se enfatiza o pone de relieve, se perfila como se conoce en gramática cognitiva, un rasgo semántico distinto del signo lingüistico o construcción involu- 
crada en el cambio. El diferente perfilamiento reflejado en cada etapa es posible porque el significado no es un todo cerrado, bien definido, sino que está abierto a recreación y redefinición constante ${ }^{63}$, lo cual permite que en cada paso de ese continuum evolutivo se perfile o enfatice un rasgo distinto, de manera que la forma en cuestión se va deslizando hacia nuevos valores y va entrando en nuevos contextos sintácticos. La posibilidad por parte del hablante de seleccionar o poner de relieve ciertos rasgos semánticos contra otros constituye un principio operativo básico de la lingüística histórica, en esa posibilidad de elección reside la esencia misma de la variación linguiistica y reside también la creatividad de la sintaxis ${ }^{64}$. En el cambio que nos ocupa, el deslizamiento del pronombre posesivo hacia un nuevo valor debió atravesar al menos tres perfilamientos: REFLEXIVIDAD > POSESIÓN > DETERMINACIón. En la etapa inicial el valor posesivo de suus era secundario y era la reflexividad el valor central; en una segunda etapa se debilita la reflexividad y se enfatiza la posesión; al hacerse central el valor posesivo, se hizo central su carácter de anáfora y su vínculo con el poseedor, pero también pasó a primer plano la opacidad de $s u(s)$ para referir al poseedor, la cual provocó que se pusieran en funcionamiento ciertas estrategias gramaticales: deixis de distancia mínima y explicitación del poseedor en su misma FN, las cuales a su vez arrojaron un nuevo perfilamiento: la determinación.

Refleja este canal de gramaticalización una dialéctica común en muchos cambios lingüisticos, a saber, una lucha entre dos tendencias encontradas complementarias constantes ${ }^{65}$ : maximizar economía, que llevó a la pérdida de $A R T+P O S+N$, o maximizar iconicidad e información, que llevó a explicitar un poseedor pospuesto. Es justo en esa dinámica dialéctica, cuyo equilibrio nunca se alcanza, donde se genera creativamente la gramática.

5. POSIBLES RESIDUOS DEL ANÁLISIS: LOS POSESIVOS DE PRIMERA Y SEGUNDA PERSONA

Hemos visto el papel protagónico que jugó el debilitamiento anafórico posesivo de la forma $s u(s)$ en el acercamiento del posesivo al artículo, con la consecuente pérdida de las construcciones $A R T+S U+N$. La pregunta obligada ahora es: ¿por qué se perdieron también los sintagmas de ART+Pos con posesivos de primera y segunda persona? Es decir, nuestro análisis plantea el siguiente resi-

${ }^{63}$ Cf. F. Lichtenberk, "Semantic change and heterosemy in grammaticalization", Language, 67, 3, 1991, págs. 475-509, especialmente págs. 505-506.

64 Cf. Company, "Motivaciones distintas para una gramaticalización", citado en la nota 2.

${ }^{65}$ Cf. Haiman, Natural syntax, citado en la nota 12 , pág. 157. 
duo: si la opacidad y debilitamiento anafórico de $s u(s)$ fueron los responsables activos de la inclusión del posesivo en la clase DET ¿por qué se perdieron también las secuencias formalmente semejantes con posesivos de primera y segunda persona, la mi casa, la nuestra casa, la tu casa, la vuestra casa, si estos posesivos ni son opacos ni son débiles en su capacidad de vincular al poseedor, puesto que su anclaje no es discursivo sino en la situación de habla?

La explicación de la pérdida de los sintagmas del tipo la mi/tu casa y sus respectivos plurales reside, a mi modo de ver, en la baja frecuencia relativa de uso de estos sintagmas y en la presión estructural que la pérdida de $A R T+S U(S)+N$ debió ejercer sobre las otras construcciones que integraban el paradigma de posesión en español. En este apartado, con base en estos dos aspectos, intentaré mostrar que la pregunta arriba formulada no constituye un verdadero residuo a nuestra hipótesis.

Por lo que respecta a la frecuencia de empleo, las construcciones con $\mathrm{ART}+M I / T U+\mathrm{N}$, y sus plurales, comparadas con las estructuras equivalentes con posesivos de tercera persona, son minoritarias en los textos medievales, tal como puede apreciarse en el cuadro $7^{66}$. Incluso, si agrupamos los posesivos de primera y segunda persona, cuadro 8 , éstos, juntos, no superan las documentaciones de posesivos de tercera persona, y éstos, en todos los períodos, duplican y hasta triplican las frecuencias de empleo de los pronombres posesivos de primera y segunda persona.

CUADRO 7

EMPLEO DE ART+POS SEGÚN PERSONA DEL POSESIVO

\begin{tabular}{llllll}
\hline & MI & TU & SU & NUESTRO & VUESTRO \\
\hline XII & $11 \%(55 / 495)$ & $16 \%(78 / 495)$ & $63 \%(310 / 495)$ & $8 \%(40 / 495)$ & $2 \%(12 / 495)$ \\
XIV & $4 \%(13 / 344)$ & $10 \%(35 / 344)$ & $77 \%(264 / 344)$ & $0 \%(1 / 344)$ & $9 \%(31 / 344)$ \\
XV & - & $3 \%(1 / 31)$ & $97 \%(30 / 31)$ & - & - \\
\hline
\end{tabular}

CUADRO 8

1. a/2. ${ }^{\mathrm{a}}$ VS. 3. ${ }^{\mathrm{a}}$ PERSONA EN LAS FNS ART+POS+N

\begin{tabular}{lll}
\hline & $1 .{ }^{\mathrm{a} / 2 .^{\mathrm{a}}}$ & $3 .^{\mathrm{a}}$ \\
\hline $\mathrm{XIIl}$ & $37 \%(185 / 495)$ & $63 \%(310 / 495)$ \\
$\mathrm{XIV}$ & $23 \%(80 / 344)$ & $77 \%(264 / 344)$ \\
$\mathrm{XV}$ & $3 \%(1 / 31)$ & $97 \%(30 / 31)$ \\
\hline
\end{tabular}

${ }^{66}$ Apud Jiménez, Las FNs con articulo+posesivo, citado en la nota 8. 
En textos poéticos, donde se esperaria una mayor explotación discursiva de construcciones gramaticales asociadas al «yo» y al «tú», las construcciones de ART+POS de primera y segunda persona siguen siendo de mucho menor empleo que aquellas con ART+SU. Los cuadros 9-11, tomados con ligeras modificaciones de Pato ${ }^{67}$, dan cuenta de estas construcciones en la poesía del Marqués de Santillana y muestran el carácter mayoritario de los posesivos de tercera persona aún en textos líricos, cuadro 9 , si bien, con respecto a los textos en prosa consignados en el cuadro 8, aumenta el empleo de las referencias de primera y segunda persona, cuando éstas se agrupan y se contraponen a los posesivos de tercera persona, cuadro 10. Lo interesante es que cuando en esos mismos textos poéticos el posesivo se emplea sólo, sin combinarse con el artículo, cuadro 11 , se equilibran las frecuencias de empleo entre las tres personas del posesivo, especialmente entre la primera y la tercera, $42 \%$ vs. $43 \%$, respectivamente, igualación que corrobora lo señalado con anterioridad, a saber, el carácter muy marcadó de las FNS con ART+POS, sea cual sea la persona del posesivo.

CuAdro 9

EMPLEO DE ART+POS SEGÚN PERSONA DEL POSESIVO EN POESIA

\begin{tabular}{lllll}
\hline MI & TU & SU & NUESTRO & VUESTRO \\
\hline $23 \%(53 / 226)$ & $13 \%(29 / 226)$ & $46 \%(103 / 226)$ & $8 \%(19 / 226)$ & $10 \%(22 / 226)$ \\
\hline
\end{tabular}

Cuadro 10

1. $1 / 2 .^{a}$ VS. 3. ${ }^{a}$ PERSONA EN LAS FNS ART+POS+N EN POESIA

\begin{tabular}{ll}
\hline $1 .{ }^{\mathrm{a}} / 2 .^{\mathrm{a}}$ & $3 .^{\mathrm{a}}$ \\
\hline $54 \%(123 / 226)$ & $46 \%(103 / 226)$ \\
\hline
\end{tabular}

CuADro 1!

EMPLEO DE POSESIVOS SOLOS EN POESIA

\begin{tabular}{lll}
\hline MI & TU & SU \\
\hline $42 \%(219 / 516)$ & $14 \%(74 / 516)$ & $43 \%(223 / 516)$ \\
\hline
\end{tabular}

${ }^{67}$ Cf. "Sobre el artículo con posesivo", citado en la nota 9. Agradezco a Errique Pato la gentileza de proporcionarme datos de su investigación en proceso. 
Dado que la frecuencia relativa de uso es siempre sintomática del valor y funcionamiento de una forma o construcción, es posible decir que el bajo rendimiento de las FNS con ART+POS de primera y segunda persona, reflejado en los cuadros 7-10, es síntoma de la mala integración de estos sintagmas en el sistema del español medieval, debido muy probablemente a que eran, aún más que las FNS con ART $+S U$, construcciones altamente definidas, sobreespecificadas, y en ellas el principio de economia, señalado como un factor de cambio en la hipótesis de este trabajo, debió hiperactivarse e inhibir aún más su empleo.

En este punto merece la pena traer de nuevo a colación el análisis tradicional de estos sintagmas con ART+POS como estructuras especializadas para énfasis y realce expresivo, cuya caracterización se sitúa en un nivel estilístico más que gramatical, dado que parecen escapar a reglas. Si analizamos la frecuencia absoluta de aparición de ART+POS en el siglo XV, cuadros 7-10, es posible percatarse de que los textos en prosa la emplean mucho menos, 31 ocurrencias, que los textos poéticos, 226 documentaciones, no obstante que el universo de palabras muestreado para prosa ${ }^{68}$ es mucho mayor que el de poesía. Aunque el corpus poético es unos cuarenta años anterior al corpus en prosa, la mucha menor frecuencia de estos sintagmas en prosa puede deberse tanto al decremento diacrónico, como muy probablemente a una explotación de carácter estilístico en poesía, lo cual apoyaría el análisis tradicional. En efecto, una característica ampliamente extendida de las lenguas es que la marcación formal suele ir de la mano con marcación semántica ${ }^{69}$, y que las formas marcadas se prestan mejor a explotación pragmática; las construcciones encabezadas con ART+POS son muy marcadas, altamente definidas, y se prestarian fácilmente a un empleo pragmático. Es decir, el análisis tradicional es acertado, pero creo debe invertirse el planteamiento: no es su carácter estilístico el que provoca la falta de un comportamiento gramatical general, sino que es su carácter muy marcado y especializado el que motiva un comportamiento gramatical huidizo y las hace formas ideales para explotación estilística.

Por otra parte, la progresiva pérdida de la estructura más frecuente, ART $+S U$, debió ejercer presión estructural para activar la pérdida de los sintagmas ART+POS de $1,{ }^{\mathrm{a}} / 2{ }^{\mathrm{a}}$, pérdida propiciada también por el muy bajo ren-

${ }^{68}$ El corpus empleado por Jiménez en su memoria de licenciatura es: para el siglo xv, la Crónica de Enrique $w$ y la Crónica de los Reyes Católicos, en una lectura exhaustiva de ambos textos.

${ }^{69} \mathrm{Cf}$, los trabajos de Haiman, "Iconic and economic motivation", y Natural syntax, y también el de J. Gvozdanovic, "Defining maskedness", Markedness in synchrony and diachrony, O. M. Tomic ed., Berlin-New York, Mouton de Gruyter, 1989, págs. 47-66, en particular las págs. 51 y $59-60$. 
dimiento ya visto de la primera y segunda persona ${ }^{70}$. Se generó en mi opinión un cambio en cadena ${ }^{71}$, en el cual la desaparición de la estructura más frecuente arrastró con ella la pérdida de las otras formas que integraban el paradigma de posesión y que compartían una distribución sintáctica semejante en el español antiguo, pero que eran de muy baja productividad. Es decir, al debilitarse la combinación ART+POS de tercera persona, se pierde una construcción importante y su cambio ejerce presión estructural y se constituye en modelo analógico para la pérdida de otras construcciones con posesivos de menor frecuencia.

\section{CONCLUSIONES}

He intentado aportar en este trabajo un nuevo ángulo de análisis que nos permita conocer un poco mejor la historia, historia aún con interrogantes, de cómo el artículo y el posesivo se amaron y desamaron en la evolución sintáctica del español. En esas afinidades y diferencias, las dos caras del signo lingüistico van de la mano, pero conllevan distinto peso en la generación de los cambios lingüísticos: la forma sienta las condiciones para que inicie un cambio, el significado decide la actualización del cambio.

Hemos visto que las necesidades comunicativas condicionan los procesos de creación de gramática: la total opacidad del posesivo en cuanto a rasgos del poseedor acarreó en la historia del español una serie de soluciones sintácticas que intentaron hacer explícita la referencia a esa entidad, pero esas soluciones, paradójicamente, acarrearon a su vez problemas: el debilitamiento anafónico del posesivo y la aproximación y reinterpretación de éste como un simple presentador de nominales. La consecuencia de ese reanálisis fue que la categoría «determinante» se amplió en el español vía la inclusión del posesivo.

Hemos visto que la actual distribución complementaria de artículo y posesivo fue generada, como la mayoría de los cambios lingüísticos, por dos fuerzas en constante y creativa contraposición: una tendencia a maximizar la economía funcional, que llevó a la pérdida de los sintagmas con artículo+posesivo, y una tendencia a maximizar iconicidad e información, que hizo necesaria la aclaración del poseedor pospuesto, misma que conllevó también el debilitamiento del posesivo como anáfora, aproximándolo a un artículo.

\footnotetext{
${ }^{70} \mathrm{Cf}$. Company, La frase sustantiva, citado en la nota 10, págs. $78-79$.

1 Cf. A. Martinet, Economie des changements phonétiques, Berne, A. Francke, 1955/1970, pág. 61 .
} 
Hemos visto también que los límites entre sincronía y diacronía se borran: la evidencia dialectal y la evidencia histórica van de la mano en la explicación de los cambios y juntas coadyuvan a la permanente creación y recreación de gramática. Recreación que se genera en el uso real de la lengua, en el discurso, y que a través de contextos motivadores termina impactando a la competencia, vía un canal de gramaticalización que no tiene fin. La frecuencia relativa de uso de una forma vs. otra en contextos similares, o de una misma forma en diferentes estados de lengua, es la mejor herramienta para observar una gramaticalización en proceso, esto es, para observar el paulatino deslizamiento de las formas hacia nuevos valores.

De manera colateral, hemos visto también que es necesario cuestionar el carácter conservador y arcaico que se le suele atribuir al español americano, ya que son precisamente algunas de estas variedades dialectales las que muestran, al menos en esta área de la gramática, las etapas más innovadoras del cambio. 